Article

\title{
Assessment of Urban Flood Resilience in Barcelona for Current and Future Scenarios. The RESCCUE Project
}

\author{
Beniamino Russo ${ }^{1,2,3, * \mathbb{C}, \text { Marc Velasco }}{ }^{1}$, Luca Locatelli ${ }^{1} \mathbb{(}$, David Sunyer ${ }^{1}$, Daniel Yubero ${ }^{1}$, \\ Robert Monjo ${ }^{4}$, Eduardo Martínez-Gomariz ${ }^{3,5}{ }^{\circ}$, Edwar Forero-Ortiz ${ }^{5}{ }^{(1)}$, \\ Daniel Sánchez-Muñoz ${ }^{6}$ (D) Barry Evans ${ }^{7,8}$ and Andoni Gonzalez Gómez ${ }^{9}$ \\ 1 AQUATEC (SUEZ Advanced Solutions), Paseo de la Zona Franca, 46-48, 08038 Barcelona, Spain; \\ marc.velasco@suez.com (M.V.); luca.locatelli@aquatec.es (L.L.); dsunyer@aquatec.es (D.S.); \\ dyuberop@aquatec.es (D.Y.) \\ 2 Grupo de Ingeniería Hidráulica y Ambiental (GIHA) (Group of Hydraulic and Environmental Engineering), \\ Escuela Politécnica de La Almunia (EUPLA, Universidad de Zaragoza) (Technical College of La Almunia, \\ University of Zaragoza), Calle Mayor, 5, 50100 Zaragoza, Spain \\ 3 Flumen Research Institute, Universitat Politècnica de Catalunya, Jordi Girona 1-3, 08034 Barcelona, Spain; \\ eduardo.martinez-gomariz@upc.edu or eduardo.martinez@cetaqua.com \\ 4 Fundación de Investigación del Clima (FIC) (Climate Research Fundation), Calle Gran Vía, 22, 28019 Madrid, \\ Spain; rma@fic.es \\ 5 Cetaqua, Water Technology Centre, Carretera d'Esplugues, 75, 08940 Barcelona, Spain; eaforero@cetaqua.com \\ 6 IREC, Power Systems department, Jardins de les Dones de Negre, 1, 2a - pl., 08930 Barcelona, Spain; \\ dsanchezm@irec.cat \\ 7 Centre for Water Systems, University of Exeter, Exeter EX4 4QF, UK; b.evans@exeter.ac.uk \\ 8 School of Built Environment, College of Sciences, Massey University, Auckland 0745, New Zealand \\ 9 Ajuntament de Barcelona (Barcelona Municipality), Carrer de Torrent de l'Olla 218, 08012 Barcelona, Spain; \\ agonzalezgom@bcn.cat \\ * Correspondence: brusso@unizar.es; Tel.: +34-932-479-869
}

Received: 26 June 2020; Accepted: 6 July 2020; Published: 13 July 2020

check for updates

\begin{abstract}
The results of recent climate projections for the city of Barcelona show a relevant increment of the maximum rainfall intensities for the period 2071-2100. Considering the city as a system of systems, urban resilience is strictly linked to the proper functioning of urban services and the knowledge of the cascading effects that may occur in the case of the failure of one or more critical infrastructures of a particular strategic sector. In this context, the aim of this paper is to assess urban resilience through the analysis of the behavior of the main urban services in case of pluvial floods for current and future rainfall conditions due to climate change. A comprehensive flood risk assessment including direct, indirect, tangible and intangible impacts has been performed using cutting edge sectorial and integrated models to analyze the resilience of different urban services (urban drainage, traffic, electric and waste sectors) and their cascade effects. In addition, the paper shows how the information generated by these models can be employed to feed a more holistic analysis to provide a general overview of the city's resilience in the case of extreme rainfall events. According to the obtained results, Barcelona could suffer a significant increase of socio-economic impacts due to climate change if adaptation measures are not adopted. In several cases, these impacts have been geographically distributed showing the specific situation of each district of the city for current and future scenarios. This information is essential for the justification and prioritization of the implementation of adaptation measures.
\end{abstract}

Keywords: urban resilience; cascading effects; climate change; pluvial floods; $1 \mathrm{D} / 2 \mathrm{D}$ coupled models 


\section{Introduction}

Urban resilience refers to the ability of an urban system —and all its constituent socio-ecological and socio-technical networks across temporal and spatial scales-to maintain or rapidly return to desired functions in the face of a disturbance, to adapt to change and to quickly transform systems that limit current or future adaptive capacity [1].

In this context, a city can be considered as a system of systems, and its urban resilience is strictly linked to the proper functioning of urban services and the knowledge of the cascading effects that may occur in the case of the failure of one or more critical infrastructures of a particular strategic sector [2]. Moreover, urban areas are complex systems that cannot be understood by sectorial and disciplinary approaches alone [3,4], and the focus of smart cities models on strengthening different sectors with technological advancement could contribute to building upon a city's resilience in terms of dealing with natural hazards [5].

This paper shows how pluvial flood urban resilience can be assessed by analyzing the behavior of critical urban services and the related cascading effects in the case of failures due to heavy storm events. With this aim, sectorial and integrated models have been developed and calibrated to analyze the resilience of several urban services in Barcelona for current (baseline scenario) and future (business as usual scenario) rainfall conditions up to the horizon of 2100 [6]. In addition, the information generated by these models, together with the historical information available for each urban service, has been used to feed a more holistic model which covers all the urban services of the city. This twofold approach, including risk treatment (implementation of adaptation strategies) in a comprehensive flood risk management process, is presented in Figure 1.

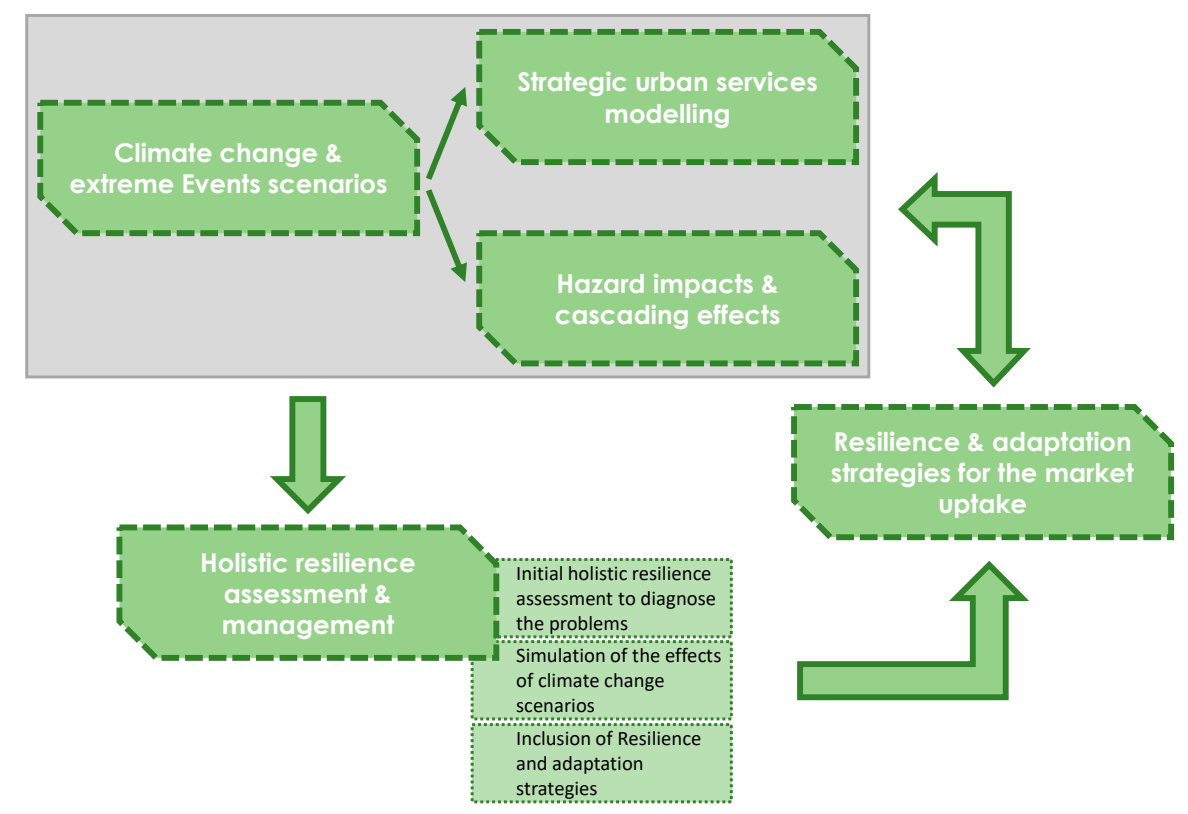

Figure 1. Twofold approach to achieve an urban resilience assessment for current and future scenarios.

A flood-resilient city can be defined as a city which is able to resist, absorb, accommodate and recover from the effects of a flood hazard in a timely and efficient manner, including through the preservation and restoration of its essential basic structures and functions [7]. In this context, flood resilience assessment has been performed in Barcelona through a 1D/2D urban drainage model linked to other urban services models to evaluate the cascade effects produced by urban floods on traffic, electric and waste collection systems. The employment of a coupled 1D/2D urban drainage model providing flow variables (flow depths, flow velocity and flood extension) on urban surfaces during pluvial flood events is essential to perform tangible and intangible risk assessments. Moreover, 
the results of these integrated models have been used to feed a holistic tool to assess the resilience of the city as a whole.

The paper proposes specific and holistic approaches to assess pluvial flood resilience in urban areas. The approaches are complementary and interconnected and can be used to understand the interrelations between urban services and infrastructures, as well as representing a valuable tool for decision making.

\section{Materials and Methods}

\subsection{The Effects of Climate Change on Maximum Rainfall Intensity in Barcelona}

Recently, the Climate Research Foundation (Fundación de Investigación del Clima; hereafter, FIC from the acronym in Spanish) provided climate projections and predictions for different climate variables in Barcelona, the results of which are summarized in Figure 2. These results confirm the same trends as other previous studies developed for the city and are in line with the data from the last Climate Plan published by Barcelona City Council [8]. According to the data provided by FIC, phenomena such as extreme rainfall, heatwaves and droughts could experience significant increases due to an acceleration of the hydrological cycle [6,9].

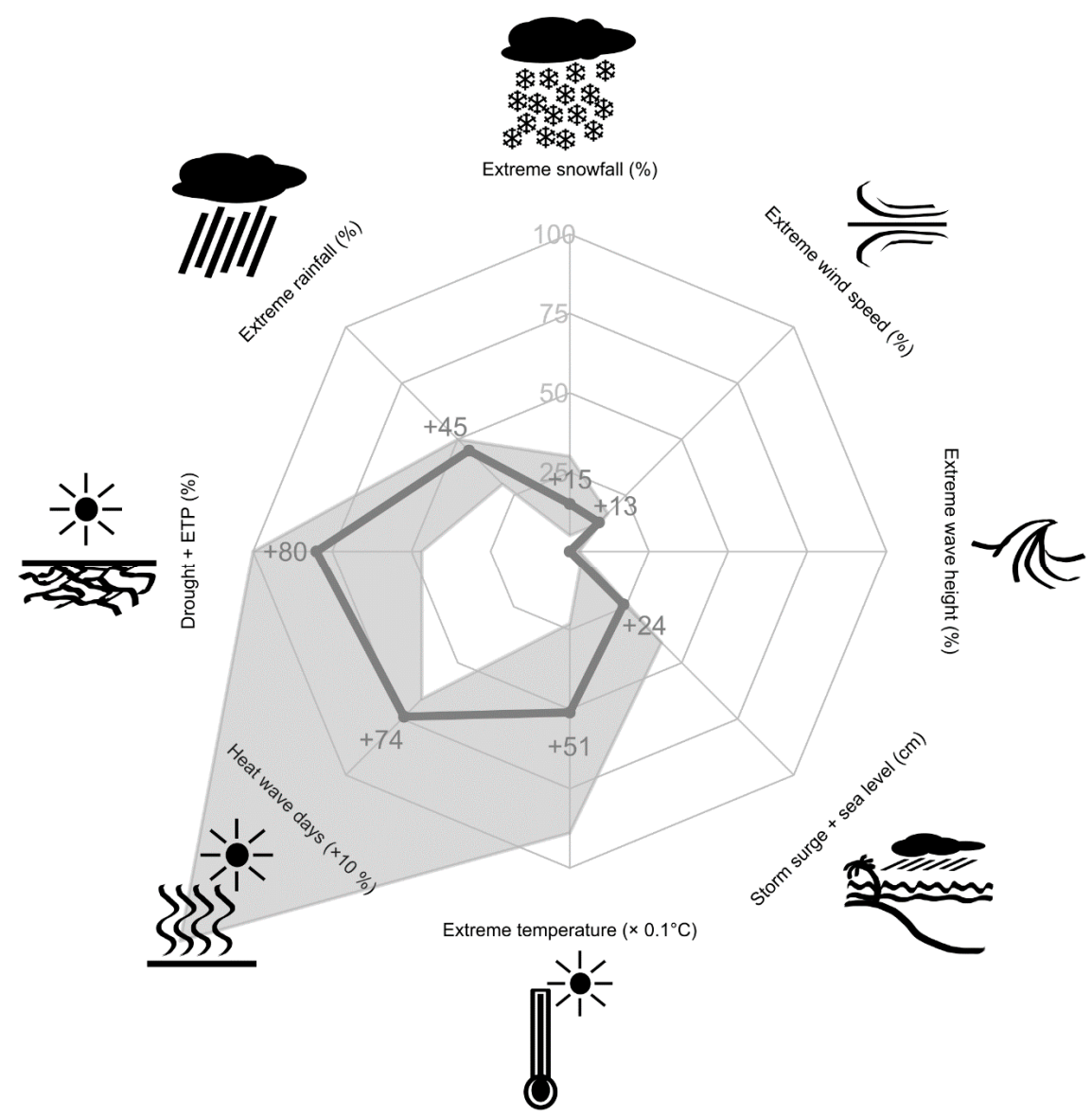

Figure 2. Extremes compass rose for Barcelona: maximum point change in extreme climate events over the century, taking into account return periods between 2 and 100 years. The center represents no changes, and the edge corresponds to an increase of $100 \%$ for every variable except for heat wave days (the border is $+1000 \%$ ) and extreme temperature (the border is $+10{ }^{\circ} \mathrm{C}$ ). Thick lines represent the median scenario, and the shaded area is the uncertainty region (5-95\%).

Particularly, in the case of maximum rainfall intensities and the horizon of 2071-2100 for the city of Barcelona, the value of the coefficient of climate change (defined as the ratio between future and 
current maximum intensities, for certain return periods and time intervals) [10,11] was found to be in a range between 1.07 and 1.26 depending on the frequency and duration of each maximum rainfall intensity (Figure 3).

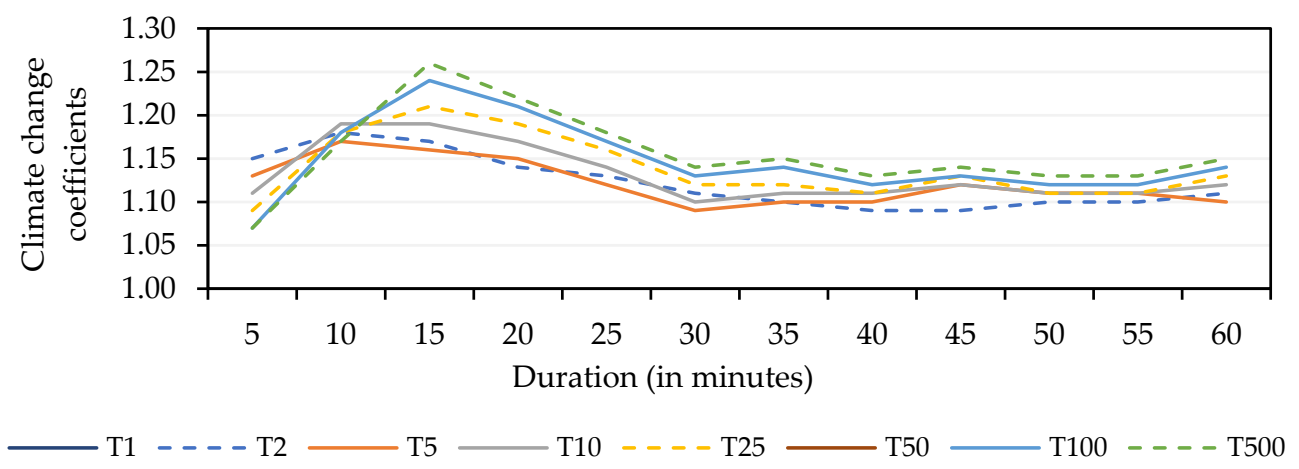

Figure 3. Fiftieth percentiles of the climate change coefficients obtained for different rainfall durations and return periods for the horizon 2071-2100 for the city of Barcelona [6].

These results were obtained using statistical spatial and temporal downscaling techniques on 20 future pluviometric series provided by 10 general atmospheric circulation models, forced by Representative Concentration Pathway (RCP) 4.5 and 8.5 scenarios and previously validated for a historical control period (1976-2005) [6]. The climate change coefficients in Figure 3 represent the 50th percentile of the results obtained.

Once these climate change coefficients were obtained, they were applied to synthetic storms with different return periods (T1, T10, T50, T100 and T500) used for the last drainage master plan of the city of Barcelona [11] obtained through the alternating blocks method. Figure 4 shows the urban drainage Barcelona project design storm for a return period of 10 years with a duration of approximately $2 \mathrm{~h}$ and $30 \mathrm{~min}$ after the application of climate change coefficients for each different rainfall duration.

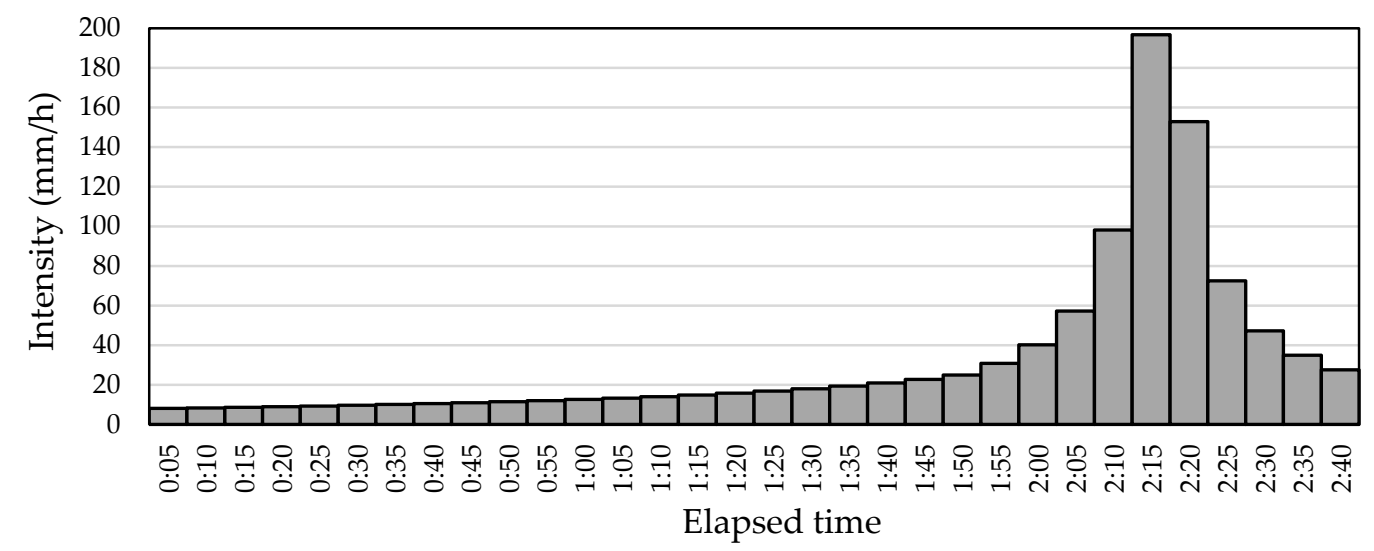

Figure 4. Urban drainage Barcelona project design storm with a return period of 10 years and a duration of $2 \mathrm{~h}$ and $35 \mathrm{~min}[6]$.

\section{2. $1 D / 2 D$ Coupled Approaches for Urban Pluvial Modelling}

Urban areas have a complex topography and contain small-scale elements such as streets and buildings that are usually not taken into account in standard river floodplain studies [12]. Therefore, a higher resolution is required to represent features at the city scale, although this may lead to larger computational time, notwithstanding the fact that urban model areas are generally smaller than a river floodplain. For all of these reasons, urban, pluvial flooding requires a different modeling approach than the one used for fluvial flooding [12]. 
During the last two decades, several authors have published papers about the need to develop and use urban stormwater models (USMs) based on coupled approaches (the modeling of the surface and sewer flows at the same time by $1 \mathrm{D} / 1 \mathrm{D}$ or $1 \mathrm{D} / 2 \mathrm{D}$ models) to represent adequately urban flood caused by surcharged sewers [13-16] and carry out realistic flood risk assessments [17].

Although the choice between using a 1D or a 2D surface overland flow model (to be coupled to a 1D sewer model) determines the accuracy of results and the computational time required to obtain them, when the flow overtops street curbs and does not remain within the street profile, using a 2D model is crucial [12,18].

In 1D/2D USMs, the underground sewer network is represented by a 1D sewer model while the surface flow is computed using a 2D model. The 2D model reproduces the urban surface topography and is essential to achieve a more realistic simulation of the flow spreading across complex urban surfaces, with results such as flow depths and velocities anywhere in the urban model area [12].

USM can be semi-distributed (SD) or fully distributed (FD). SD models, commonly applied in urban stormwater modeling, are based on subcatchment units where rainfall is applied, while runoff is estimated and routed according to specific hydrological losses and rainfall-runoff transformation methods. FD models, which are generally more detailed and theoretically more realistic, are based on the two-dimensional (2D) discretization of the overland surface, where runoff volumes are estimated and directly routed by the 2D overland flow module [19]. Both kinds of approaches can be followed to create 1D/2D coupled models that are able to simulate, at the same time, the behavior of the sewer system and the urban surfaces and their mutual interaction in case of pluvial flooding events (Figure 5). Finally, hybrid models $(\mathrm{H})$ can account for runoff produced by rainfall which is directly applied from subcatchment units formed by building areas (roofs, terraces and courtyards) and directly conveyed into the sewer systems; for the other impervious (streets, sidewalks, squares, etc.) and pervious (parks and natural areas) urban surfaces, the 2D overland flow model computes and routes the runoff produced by the rainfall directly applied to these surfaces [20]. These approaches are represented in Figure 5.

$$
\text { Rainfall }
$$

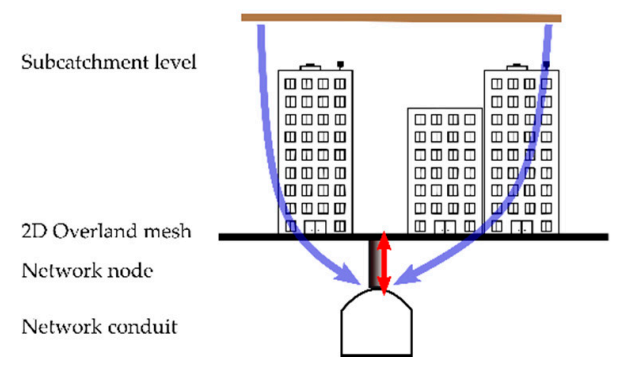

(a) SD
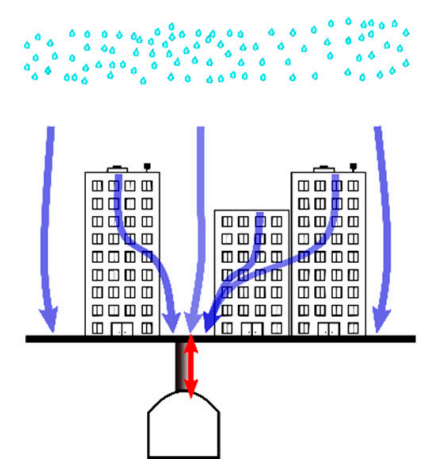

(b) FD

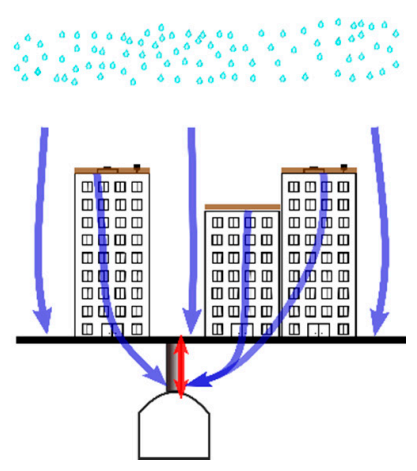

(c) $\mathrm{H}$

Figure 5. Scheme of semi-distributed (SD) (a), fully-distributed (FD) (b) and hybrid (H) (c) 1D/2D coupled urban stormwater model (USM) approaches (adapted from [19]). In brown, subcatchment units are represented, while blue lines and arrows indicate the pathway of the runoff from the source (subcatchment units or discretized 2D surface) to the sewer system.

The amount of runoff entering the underground sewer network is limited by the hydraulic efficiency of surface drainage structures (inlets, transversal grates, etc.) [21-23] and their state of maintenance and clogging [23,24], although these aspects are often neglected in urban drainage models [19]. Generally, SD models apply all the runoff estimated in a given subcatchment directly into the selected computational node of the sewer system, without accounting for the hydraulic capacity of surface drainage capacity. With this assumption, this kind of model only considers the flooding that occurs when the sewer system surcharges and neglects urban floods produced by the 
poor capacity of inlet systems [19]. On the contrary, FD modelling packages, such as Infoworks ICM (Integrated Catchment Modeling) software [25], can take into account the hydraulic performance of surface drainage systems connecting network nodes with the $2 \mathrm{D}$ overland surface mesh by weirs, orifices and other experimental equations [20,21].

\subsection{Barcelona Semi-Distributed 1D/2D USM}

After the two first investigations concerning the development and calibration of a detailed 1D/2D USM in Barcelona, covering approximately half of the administrative land of the city (more than $50 \mathrm{~km}^{2}$ ) [20,26], a new SD model has been developed and calibrated in the framework of this work [2] and the new drainage master plan of the city (PDISBA, from the acronym in Spanish) $[11,27]$.

The large amount of effort related to the analysis of the deficit of surface drainage systems through the last two drainage master plans of the city and the consequent implementation of thousands of inlets in all the urban catchments allow the assumption that stormwater could be quickly introduced into the sewer system by avoiding uncontrolled runoff circulation and aiming to develop an SD 1D/2D USM (referred to as 1D/2D USM in the following).

Moreover, the new 1D/2D USM presents two relevant improvements with respect to the previous ones: the model includes the main and secondary sewer network, reaching a total length of $1650 \mathrm{~km}$ of pipes, and covers the whole hydrological area of the city (administrative land and upstream surfaces), exceeding $120 \mathrm{~km}^{2}$ of model domain.

The model, with more than 85,000 nodes and a discretized 2D domain in an unstructured mesh of more than 1,360,000 cells, was developed through the Infoworks ICM (Integrated Catchment Modeling) software (www.innovyze.com) [25] and was calibrated and validated using the historical data recorded by more than 100 flow depth gauges located in the city's sewage network and more than 20 rain gauges distributed in the analyzed domain using Thiessen polygons [11,27]. The average size of the 2D cells for overland flow modeling is in the range of $25-100 \mathrm{~m}^{2}$.

The model required high-quality topographic information (physical data from the network, digital terrain model $2 \times 2 \mathrm{~m}$ with a resolution in height of approximately $15 \mathrm{~cm}$ ) and phenomenological information (rainfall data and flow level for the calibration phase), in addition to an adequate hardware configuration to reduce computation time during numerical simulations [20].

The new 1D/2D USM allowed the estimation of flow variables (flow depth, flow velocity and flood extension) on the surface prone areas by several numerical simulations of historic events and synthetic storm hyetographs for current and future scenarios. These values were used for the flood hazard and intangible risk assessment (concerning pedestrian and vehicular circulation) and the evaluation of tangible direct and indirect impacts. The same outputs were also used to feed other integrated models of critical urban services to assess the cascading effects of floods in these sectors.

\subsection{Modeling of the Effects of Pluvial Floods on Several Urban Services}

Projections of rainfall and sea level rise were used to feed the 1D/2D coupled USM to analyze the hydraulic behavior of the underground sewer system and the overland flood-prone areas in the case of pluvial floods for current and future rainfall conditions.

Concerning the assessment of multiple hazards and risks, the proposed methodology is based on the development of coupled models and tools ("loosely or integrated models"); thus, the outputs of certain models are used as inputs in others according to the scheme presented in Figure 6 [27]. 


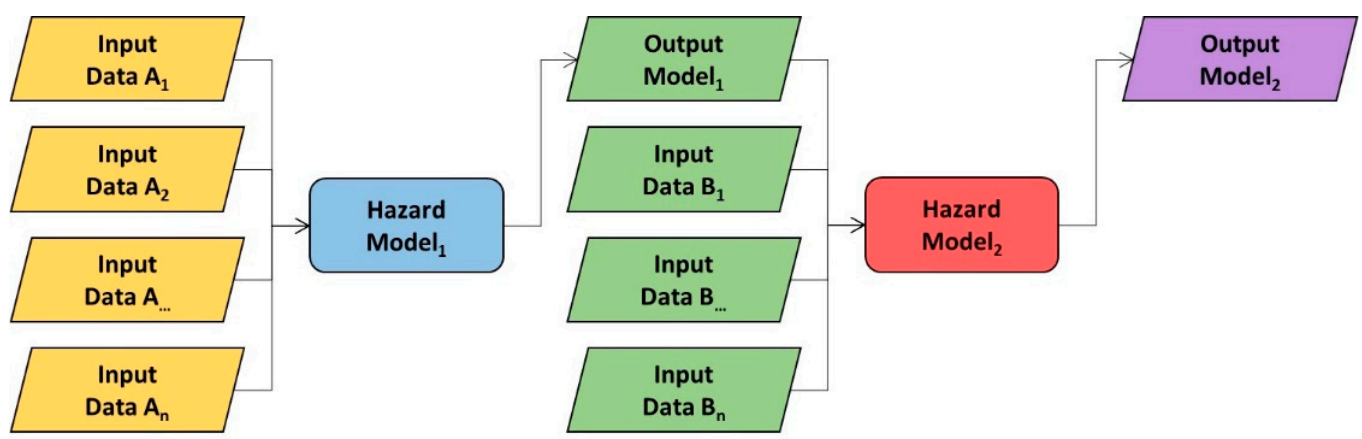

Figure 6. Scheme of loosely coupled model approach used for the multi-hazards assessment [27].

The aim of the developed loosely coupled models was the assessment of multi-hazards and multi-risks (including direct and indirect impacts) produced by urban pluvial floods and the cascading effects on other urban services (electrical system, waste collection system and surface traffic system). Table 1 summarizes the analyzed services affected by pluvial floods in Barcelona, the behavior of which was based on the developed loosely coupled models [27]. Figure 7 shows the analyzed interrelationships to assess the resilience of some main city services in the case of urban flooding episodes [28].

Table 1. Loosely coupled models developed and used for the flood resilience analysis in Barcelona.

\begin{tabular}{ccc}
\hline Loosely Coupled Model & Involved Sectors & Main Purposes \\
\hline 1D/2D coupled model & Urban drainage & $\begin{array}{c}\text { Flood hazard assessment and socio-economic } \\
\text { flood risk assessment for people and properties }\end{array}$ \\
\hline Flooding—traffic model & Urban drainage and surface traffic & $\begin{array}{c}\text { Assessment of flood hazard and flood impacts on } \\
\text { traffic system }\end{array}$ \\
\hline $\begin{array}{c}\text { Flooding—electric model } \\
\begin{array}{c}\text { Flooding—waste collecting } \\
\text { model }\end{array}\end{array}$ & Urban drainage and electric system & $\begin{array}{c}\text { Assessment of flood hazard and flood impacts on } \\
\text { electric system }\end{array}$ \\
\hline
\end{tabular}

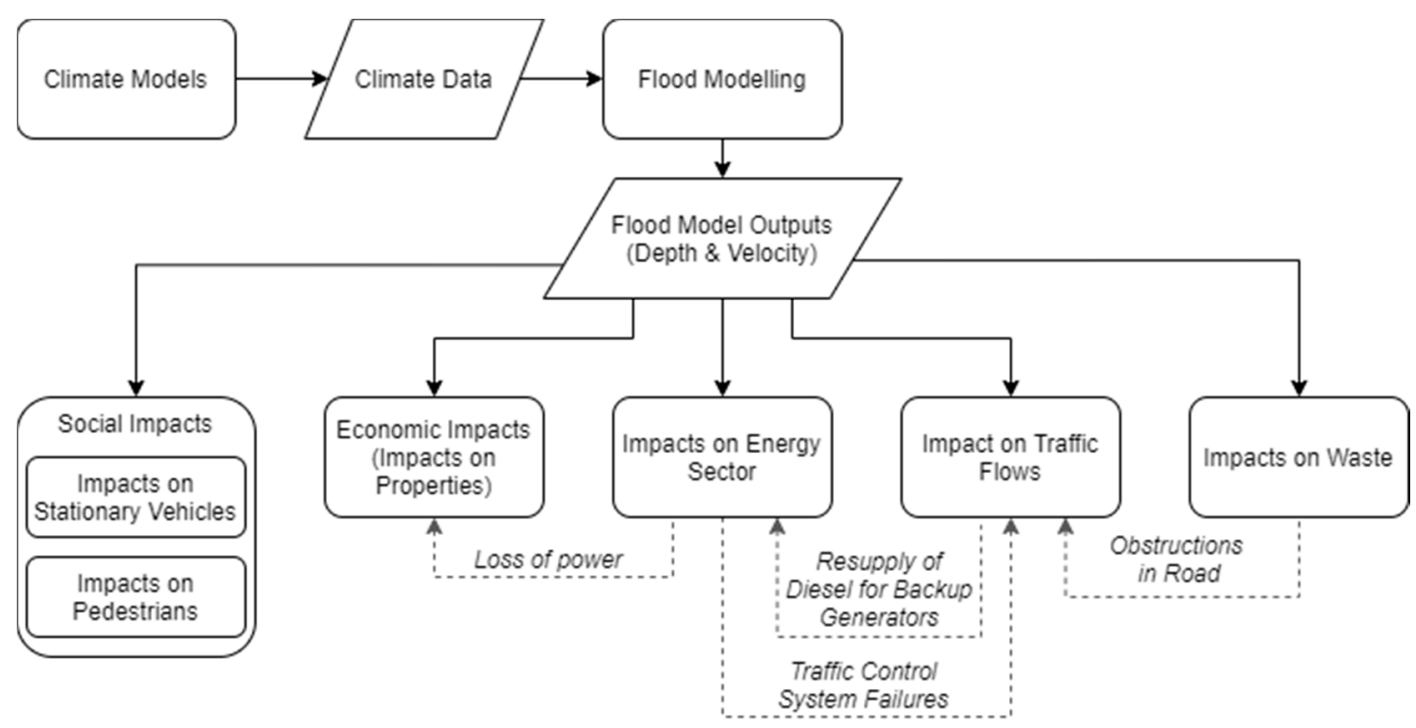

Figure 7. Diagram of the impact analyses carried out within this paper and the potential cascading effects.

\subsection{Social Flood Impacts Model}

Pluvial flood impacts can be classified into tangible and intangible impacts and direct and indirect impacts [29]. In this study, socio-economic impacts produced by pluvial flooding have been assessed 
according to comprehensive and detailed methodologies carried out and implemented in previous investigations in several urban areas $[29,30]$.

In the social field, for the assessment of the intangible impacts, human risk focuses on the safety of pedestrians and vehicles exposed to pluvial flooding events. Risk is defined as the combination of hazard and vulnerability according to the approach proposed by Turner et al. [31] and implemented in previous studies $[29,30]$. According to this, hazard assessment is based on the severity and frequency of the hydrodynamic variables and is classified based on specific flood hazard experimental criteria regarding pedestrian and vehicular stability in urban flooded areas (Figure 8) [27,32-34].

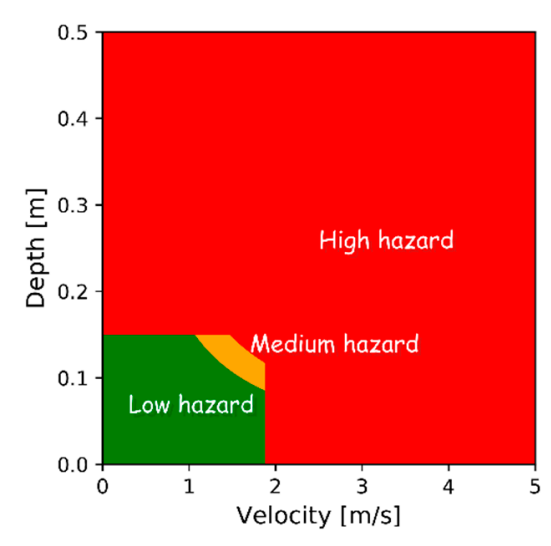

(a)

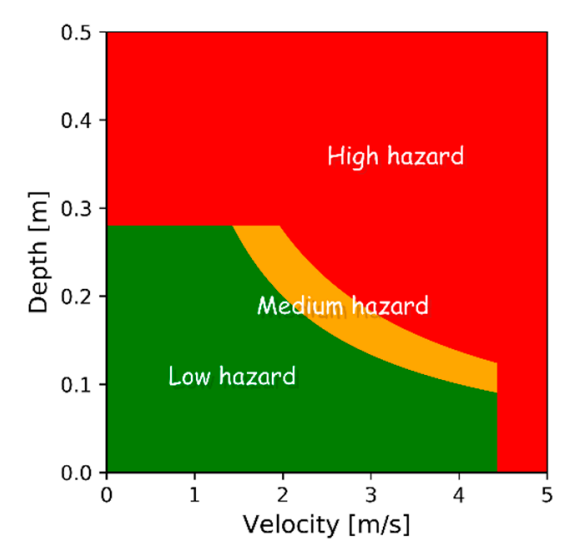

(b)

Figure 8. Experimental flood hazard criteria for (a) pedestrians and (b) vehicles.

Regarding flood vulnerability for pedestrians, it is considered to be a function of exposure and sensitivity, taking into account several indicators such as demographic density, the percentage of people of a critical age and of foreign inhabitants and the number of critical infrastructures. By setting thresholds for the proposed indicators, the vulnerability of each census district can be qualitatively scored and classified as low, medium and high. On the other hand, in order to assess the vulnerability for vehicular circulation, the exposure for each urban street, expressed in terms of vehicular daily intensity, is considered. Based on this value, flood vulnerability regarding vehicular circulation is qualitatively scored and classified as low, medium and high, in a similar manner to pedestrian vulnerability [28-30].

Methods for risk determination can be qualitative or quantitative, with both having limitations. If we define risk as the probability or threat of a hazard occurring in a vulnerable area, flood risk can be assessed through a flood risk map related to a determined scenario and return period by combining hazard and vulnerability maps $[29,30]$. Pedestrians and vehicles are expected to be the most potentially affected by floods in Barcelona. Their risk is related to their stability, and in Barcelona, this is assessed for the present (baseline) and also for the future (business as usual (BAU)) scenarios according to the rainfall variable projections for different return periods.

Qualitative risk assessment defines hazards, vulnerability and risk levels by significance levels such as "high", "medium" and "low" and evaluates the resultant level of risk against qualitative criteria. In this case, hazard and vulnerability maps are generally elaborated through specific criteria and indexes, and so risk maps will be created by multiplying the vulnerability index $(1,2$ or 3 , corresponding to low, medium and high vulnerability) by the hazard index $(1,2$ or 3 , corresponding to low, medium and high hazard). Finally, the total risk varies from 1 to 9 , where higher levels indicate higher risk according to the following risk matrix (Figure 9) previously employed in other works $[29,30]$. 


\begin{tabular}{ccccc}
\hline & \multicolumn{3}{c}{ Hazard } \\
\cline { 2 - 5 } & Low & Medium & High \\
\hline \multirow{3}{*}{ Vulnerability } & Low & Low & Medium \\
\cline { 2 - 5 } & Medium & Low & Medium & High \\
\cline { 2 - 5 } & High & Medium & High & High \\
\hline
\end{tabular}

Figure 9. Proposed flood risk matrix for pedestrians and vehicles $[28,30]$.

\subsection{Economic Flood Impacts Models}

Regarding economic flood risk assessment in Barcelona, tangible direct and indirect damage were considered [28]. Specifically, tailored flood depth-damage curves were developed for the case of Barcelona [35,36] and used to feed a detailed damage model regarding properties and vehicles (the two most affected assets by pluvial floods in the city). The model was already successfully applied for the city of Badalona $[30,37]$ and validated using insurance claims according to the data received from the Spanish public insurance company "Consorcio de Compensación de Seguros (CCS)" [28]. This public entity covers all the damage produced by extraordinary events, such as damage related to natural hazards (e.g., pluvial floods). On the other hand, indirect damages were assessed by an econometric model, achieving a constant relation between direct and indirect tangible damage. This model was also validated using field data [28].

\subsection{Integrated Flooding-Surface Traffic Model}

The simulations related to the integrated flooding-surface traffic model in Barcelona were carried out using a mesoscale model and the TransCAD Transportation Planning software (https: //www.caliper.com/tcovu.htm) adopted by city council's mobility department (https://www.caliper. com/tcovu.htm) [38]. The mesoscale model simulated the vehicular flow in each link of the street network; each link contained detailed information regarding the volume of traffic, its typology (for example: number of cars, trucks, bicycles, etc.), travel time, the residual capacity of the section, etc. Flood maps produced through the city's 1D/2D USM were used as inputs for a dynamic traffic model to estimate the effects within the city's surface transportation network produced by pluvial floods. A recent study developed by Pyatkova et al. [39] analyzed how the flow depth information can be used as criteria to approximate the reduction of vehicular free-flow speeds to $20 \mathrm{kmh}^{-1}$ along streets that have standing water, with a reduction to $0 \mathrm{kmh}^{-1}$ where the water depths exceed a threshold value (Table 2). As previously mentioned, the mesoscale traffic model contained information on a wide number of parameters relating to traffic flows for each road section, including the maximum speeds allowed on each section. To simulate the effect of flooding within the traffic model, we needed to adjust the maximum allowable speed parameters based on food model outputs. This approach involved using geospatial analysis as a precursor to modify the input data of a traffic model, as outlined in Evans et al. [38], where the outputs from the 1D/2D USM were used to spatially define vehicular speed restrictions along the road network. The results from the traffic model run under flooded conditions were compared to the benchmark traffic model (the traffic model run under dry weather conditions) and the impacts in terms of relative disruption to traffic flows were analyzed.

Table 2. Flood hazard effects on traffic flow (from [38,39]).

\begin{tabular}{ccc}
\hline Flood Depth Range $(\mathbf{m})$ & Hazard Classification & Maximum Vehicle Speed $(\mathbf{k m} / \mathbf{h})$ \\
\hline Flow depth $<0.1$ & Low & Road speed limit \\
\hline $0.1<$ Flow depth $<0.3$ & Medium & 20 \\
\hline Flow depth $>0.3 \mathrm{~m}$ & High & 0 (Road closed) \\
\hline
\end{tabular}


Here, flood hazard analysis was performed by a GIS (Geographic Information System) spatial analysis of the flooded road links; the rules applied in relation to traffic speed reductions are outlined in Table 2, and the flow depths were provided by the 1D/2D coupled USM. The results of this analysis were used to select and modify the maximum allowable speed limits for flooded roads within the traffic model based on the flood hazard. Using these new input parameters, the traffic model was run and the results compared to the normal (dry weather) traffic modelling conditions. Detailed information about the approach can be found in the work published by Evans et al. [38].

\subsection{Integrated Flooding-Electric System Model}

This model analyzed the potential effects of pluvial floods on the electrical system of the city of Barcelona, with special emphasis on critical infrastructures such as high and medium-voltage substations, as well as distribution centers, taking into account the possible effects of climate change.

The model was designed for the hazard, risk and cost assessment of the electrical assets, as shown in Figure 10.

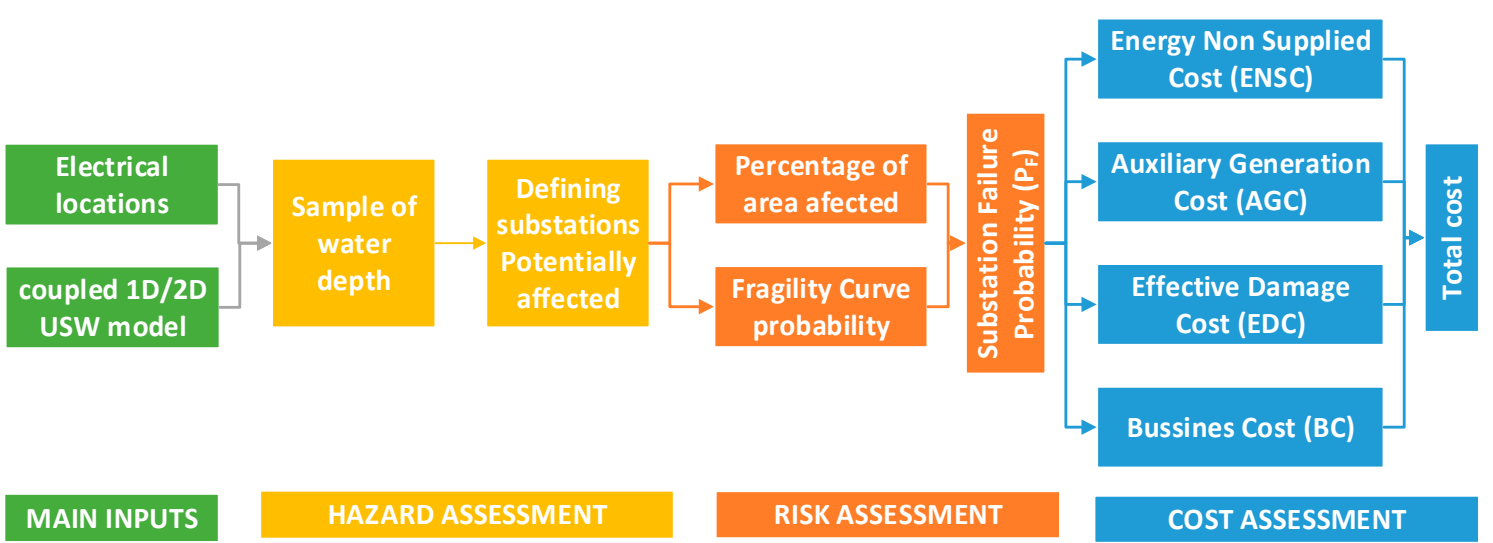

Figure 10. Integration of GIS spatial analysis for flood assessment on the electrical model.

In particular, the flooding hazard level of each electrical infrastructure was assessed on the basis on flood influence areas of $5 \mathrm{~m}, 25 \mathrm{~m}$ and $30 \mathrm{~m}$ in radius with respect to their location depending on the asset type (distribution center (DC), medium-voltage (MV) and high-voltage (HV) substation respectively), as well as considering the flow depths values every $2 \mathrm{~m}$ in order to avoid local errors and potential uncertainties of the electrical asset location and of the source data provided by the $1 \mathrm{D} / 2 \mathrm{D}$ USW model. In addition, a $10 \mathrm{~cm}$ threshold was used to consider significant local flooding. Using these parameters, the flood affections were classified as complete, partial or null, quantifying the percentage of flooded surface in each area of influence of each electric infrastructure according to the methodology proposed by Sánchez et al. [28,40].

One of the most important uncertainties of this model was the lack of knowledge about the specific location of critical electrical infrastructures (sometimes located on surfaces and at other times underground or with self-protection elements which were not always known).

For the impacts analysis, a vulnerability curve (known as a fragility curve in the energy sector) of the electrical infrastructure proposed by the Federal Emergency Management Agency [41] was used. The curve relates the probability of failure of an electrical infrastructure to the flood depth. Furthermore, this curve was partially modified to carry out a sensitivity analysis of the final results regarding this input [40]. The results obtained from the analysis of the percentage of flooding surface in each area and from the fragility curve were computed to obtain a probability of failure, later categorized into four different risk categories as shown in Table 3. 
Table 3. Failure probabilities for electrical assets.

\begin{tabular}{cc}
\hline Probability Range & Categorical Description \\
\hline$P_{F}<0.01$ & Low Failure Probability (LFP) \\
$0.01<P_{F} \leq 0.1$ & Moderate Failure Probability (MFP) \\
$0.1<P_{F} \leq 0.5$ & High Failure Probability (HFP) \\
$P_{F}>0.5$ & Non-Acceptable Failure Probability (NAFP) \\
\hline
\end{tabular}

The cost assessment was based on estimations based on GIS computing; furthermore, we established the supply area of each electrical location using Thiessen polygons and obtained the power supplied through an estimation of the consumers per area based on the census of the city.

Based on these estimations, it was possible to extract the number of consumers affected and the time needed to repair the substation as well as the cost of the energy not supplied, the cost incurred by businesses, auxiliary generation and the damage received by the location [40].

\subsection{Integrated Flooding-Waste Collection System Model}

In the case of pluvial floods, waste containers can lose their stability due to buoyancy, dragging or overtopping, thereby allowing debris and leachate to escape from the containers and contaminate the floodwater and the environment [42]. On the other hand, the containers displaced by the flow can obstruct superficial drainage pathways or obstruct narrow streets, exacerbating the effects of the flood. Consequently, waste containers' stability in the case of pluvial flooding is definitely an environmental, safety and health concern which needs to be addressed in a context of urban flood resilience assessment.

In order to analyze the significance of this problem in Barcelona, an integrated flooding-waste collection system model was developed and validated. In the city, there are more than 27,000 containers, which can be classified according to the type of waste they contain (waste, organic, paper and cardboard, plastic and packaging and glass), their volume in liters (3200, 3000, 2400, 2200 and $1800 \mathrm{~L}$ ) or the manner in which they can be loaded (lateral, bilateral, rear or underground) (Figure 11) [27,42]. In order to study the stability of these containers, stability curves depending on the type of container, their filling degree and the overland flow parameters (flow depth and velocity) were created [42].

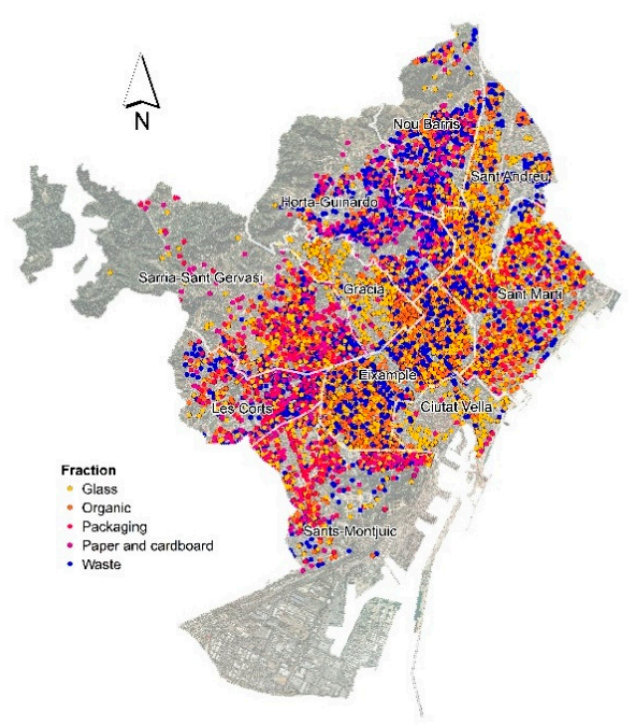

(a)

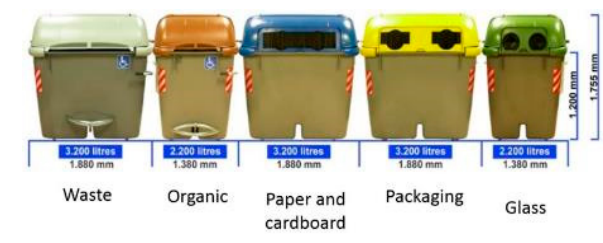

(b)

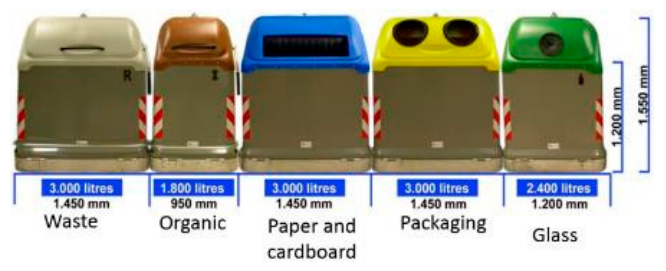

(c)

Figure 11. (a) Container distribution in Barcelona classified according to fraction type and types of containers as they are loaded by the bin lorry, (b) lateral load and (c) bilateral load. Adapted from Martínez-Gomariz et al. [42]. 
Finally, on the basis on the location of the containers (Figure 11) and the flow parameters provided by the 1/D/2D USM model, flood hazard maps showing the unstable waste containers were created for an historical storm event to validate the model and several synthetic project storms of 1, 10 and 50 years $[27,42]$.

\subsection{Holistic Model of Urban Resilience}

The information and the results provided by the 1D/2D USM were used as inputs to the HAZUR ${ }^{\circledR}$ holistic tool for the evaluation of the potential cascading effects produced by pluvial floods on several main urban services (as well as others not contemplated by the integrated flood models previously described) and to estimate their recovery time for current and future scenarios. This analysis involved 34 urban services grouped into nine sectors with 563 critical infrastructures. The main urban sectors and services analyzed included the water cycle, energy, telecommunications, transport, emergencies, public health, environment and green infrastructures, waste and citizens. The HAZUR ${ }^{\circledR}$ tool is capable of analyzing cascading effects generated from certain impacts (Figure 12). In the case of pluvial floods, impacts and cascade effects on electric and transport sectors were assessed for several synthetic project storms with different return periods (T1, T10, T150, T100 and T500) for current (baseline) and future (BAU) scenarios.

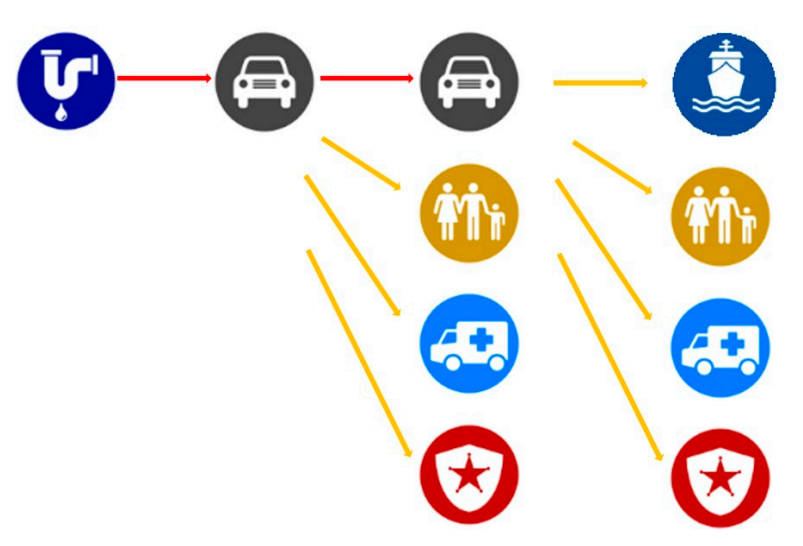

Figure 12. Cascading effects simulated by $H A Z U^{\circledR}{ }^{\circledR}$ for a pluvial flood with a 10 year return period in Barcelona.

Taking into account the down-times included in the HAZUR ${ }^{\circledR}$ tool (obtained from the sectorial models or by expert assessment) and considering the interdependencies which exist between several services and infrastructures, the cascading effects can be simulated [43]. Figure 12 presents an example of cascading effects generated by a 10 year return period flood event in Barcelona. In this case, as can be seen in Figure 12, the tool allows us to see that the lack of capacity of the drainage system in the upper part of the city generates a flood on the high-speed ring "Ronda de Dalt", stopping the circulation of vehicles. This affects many other services (such as medical emergency services, the local police or the citizens), and it also causes the failure of the other high-speed ring "Ronda Litoral", which in turn would affect the same services as before (in another area of the city) as well as the port of the city due to the connection of this highway with that infrastructure.

\section{Results}

The 1D/2D USM and the derived loosely coupled (integrated) models described in the previous section were developed and validated using field data provided by sensors and historic collected information to estimate the potential effects of climate change on the urban drainage sectors and the cascading effects on other main urban services [27]. The use of this modeling approach allowed us to achieve valuable results in terms of flood hazards, as well as in terms of socio-economic risk and impacts on other sectors of the city. In this section, the specific results directly related to the urban 
drainage sector and the other analyzed urban services (surface transport, electric system and waste collection) are presented.

\subsection{Assessment of Social Impacts Produced by Pluvial Floods}

\subsubsection{Flood Risk for Pedestrians}

The hydraulic behavior of the urban drainage system of the city (considering both the hydraulic response of the sewer network and the overland flow on the urban surfaces) was simulated using the 1D/2D USM for a large set of synthetic projects storms with return periods T of 1, 10, 50, 100 and 500 years for current and future scenarios. As our first results, following the specific flood hazard criteria for pedestrians presented in Section 2.5, detailed flood hazard maps were created.

The results also allowed the estimation of flood hazards for pedestrians for each district of the city (with a total area of approximately $102 \mathrm{~km}^{2}$ ) and their evolution in the case of a climate change scenario. The results concerning the current scenario show that areas classified as having high flood hazard conditions have reduced risk for low return periods (null for $\mathrm{T}=1$ and less than $5 \%$ for $\mathrm{T}=10$, with this last one being the designed return period for the sewer system of the city), which progressively increases for higher return periods. This notwithstanding, the results show that climate change scenarios could produce an increase in high flood hazard areas of between $20 \%$ and $50 \%$. Additionally, for the simulation corresponding to return period $\mathrm{T} 1$ and BAU scenario, the high flood hazard area is null for each district [28].

To assess the flood risk for pedestrians, flood hazard was combined with the human vulnerability, which was achieved according to the indicators mentioned in Section 2.5 (details can be found in [28]). Vulnerability was qualitatively assessed for each census district in low, medium and high levels. These classification ranges resulted in the vulnerability map presented in Figure 13, which was also considered for BAU due to the mainly consolidated urbanistic characteristics of the city [28].

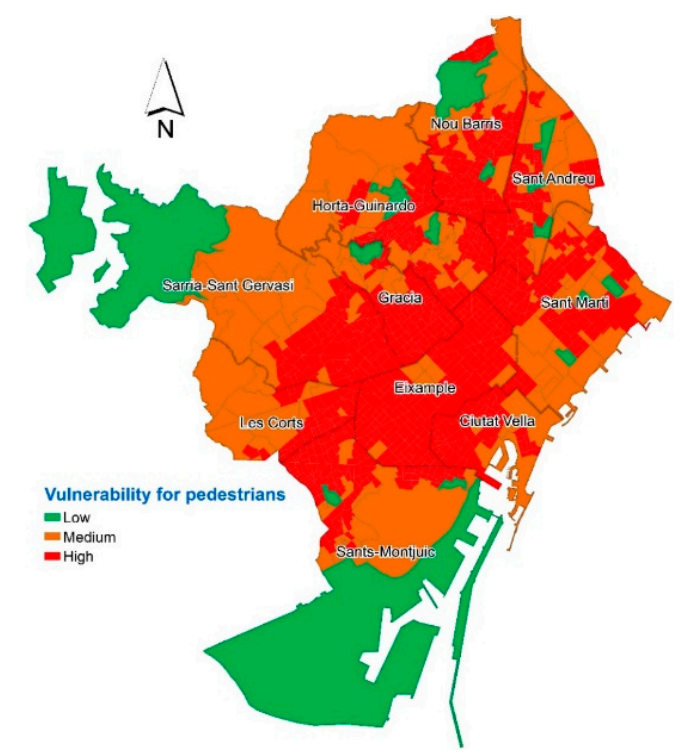

Figure 13. Vulnerability maps for pedestrians.

As stated above, the flood risk results were presented in terms of flood risk maps for all the considered return periods and scenarios (baseline and BAU). Figure 14 shows the flood risk maps related to a rainfall storm event with a return period of 10 years for both scenarios. 


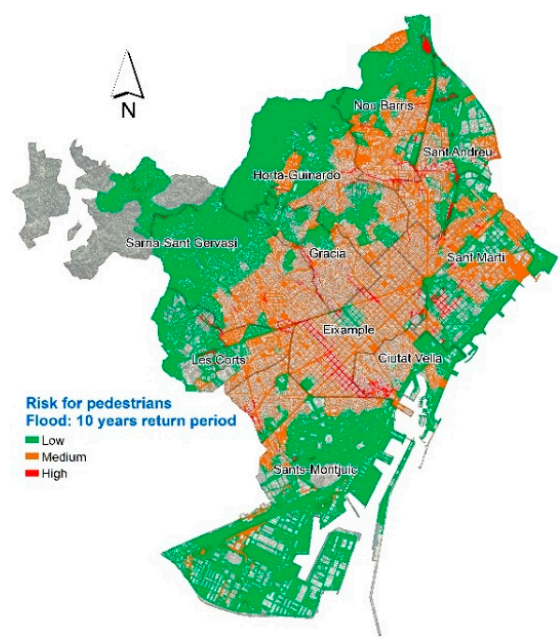

(a)

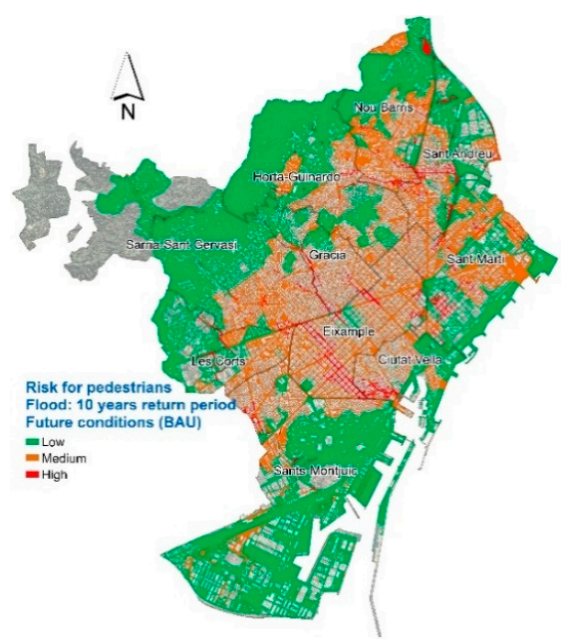

(b)

Figure 14. Example of flood risk maps for pedestrians for a synthetic 10 year return period projected storms related to (a) baseline and (b) business as usual (BAU) scenarios.

Furthermore, the high-risk area (in percentage) for pedestrians was broken down into districts in order to observe the riskiest districts in terms of pedestrians' stability. Moreover, in order to highlight the effect of climate change in terms of the increase of high-risk areas in Barcelona, we also present the variation of high flood risk areas for pedestrians according to the 10 districts into which Barcelona is administratively divided (Figure 15). It is possible to observe the major increases of high flood risk areas (around 30\% for the whole district of Barcelona) with respect to the climate change coefficients (from $12 \%$ to $16 \%$ ) for the same return periods [28].

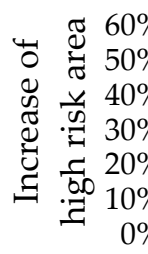

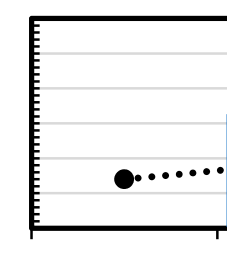

$\mathrm{T} 1$

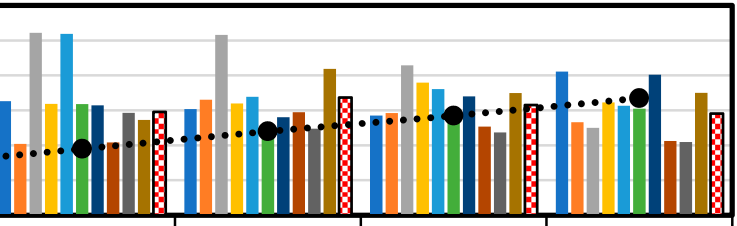

$\mathrm{T} 10$

$\mathrm{T} 50$

$\mathrm{T} 100$

T500

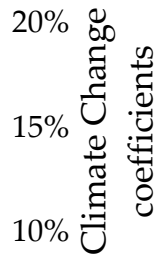

Floods related to return periods
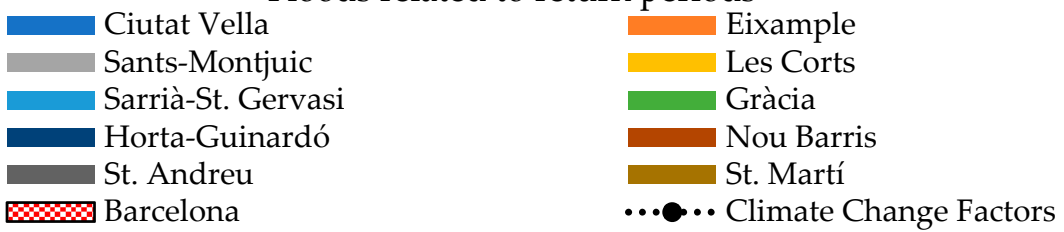

Figure 15. Expected increase of high-risk areas according to the future conditions.

\subsubsection{Flood Risk for Vehicles}

The flow variables (flow depths and flow velocity) provided by the 1D/2D USM were also used to generate flood hazard maps for vehicles for each district of the city and their evolution in the case of a climate change scenario. The results concerning the current scenario show that areas classified with high flood hazard conditions have reduced risk compared to the case of pedestrians; in particular, high hazard is null for $\mathrm{T}=1$ and is less than $5 \%$ for $\mathrm{T}=10$, with this last one being the designed return period for the sewer system of the city, which progressively increases for higher return periods. This notwithstanding, the results show that climate change scenarios could produce an average increase of $30 \%$ for the whole city with a peak of $50 \%$ for specific districts. Additionally, for the simulation 
corresponding to return period T1 and the BAU scenario, the high flood hazard area is null for each district [28].

In order to assess the vehicles' vulnerability, three levels were also proposed based on a unique indicator: The vehicular flow intensity (VFI) expressed in veh/day. Depending on this value and defined thresholds, the vulnerability of each urban road was classified into three levels (low, medium and high) [28]. The final vulnerability map is shown in Figure 16.

Furthermore, for vehicles, flood risk was assessed through the elaboration of flood risk maps for all the considered return periods and scenarios (baseline and BAU). Figure 17 shows the flood risk maps related to a rainfall storm event with a return period of 10 years for both scenarios.

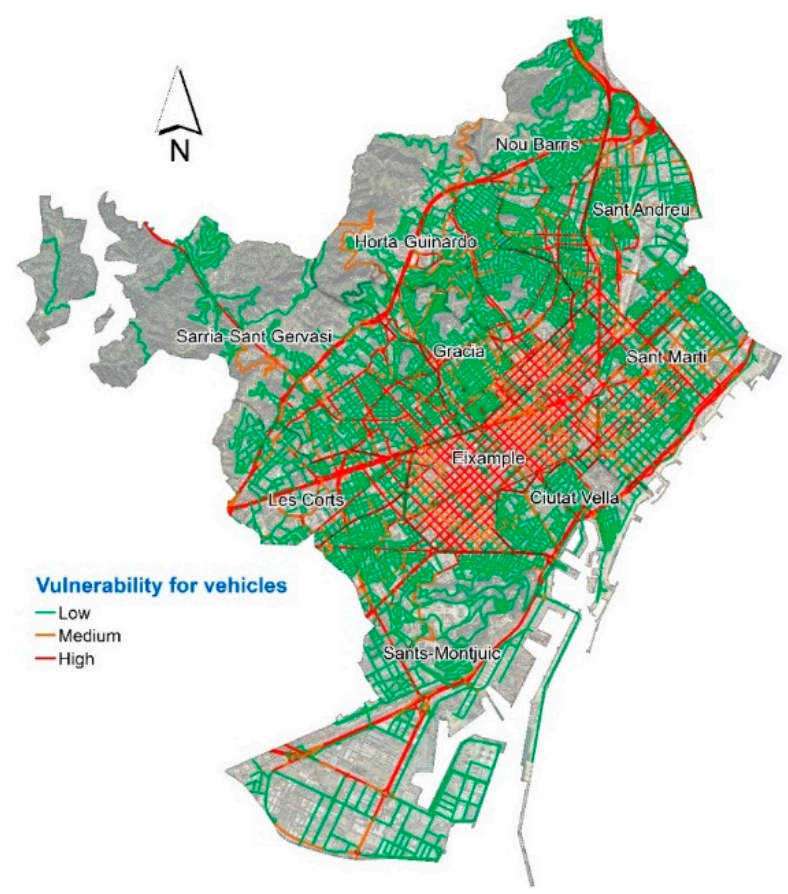

Figure 16. Vulnerability map for vehicles. Green, orange and red colors indicate low vulnerability (vehicular flow intensity (VFI) < 100), medium $(100<$ VFI < 1000) and high (VFI > 1000), respectively.

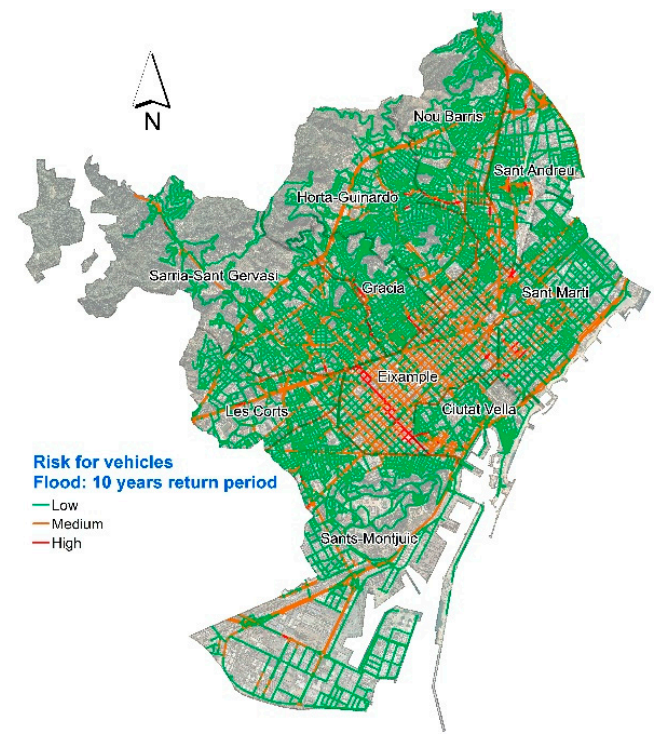

(a)

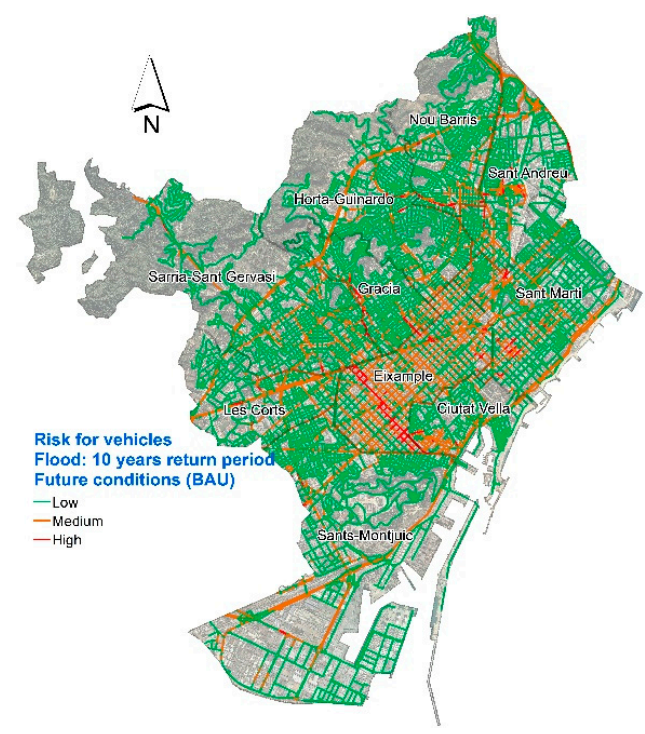

(b)

Figure 17. Example of flood risk maps for vehicles for synthetic 10 year return period projected storms related to (a) baseline and (b) BAU scenarios. 
In this case, the assessment has also been broken down into districts in order to observe the riskiest districts in terms of vehicles' stability. Moreover, in order to highlight the effect of climate change in terms of the increase of high-risk areas in Barcelona, we present the variation of high-flood risk areas for vehicles in all of the districts (Figure 18). In this case, it is also possible to observe a major increase of high flood risk areas (from $20 \%$ to $40 \%$ for the whole city area) with respect to the climate change coefficients (from $12 \%$ to $16 \%$ ) for the same return periods.
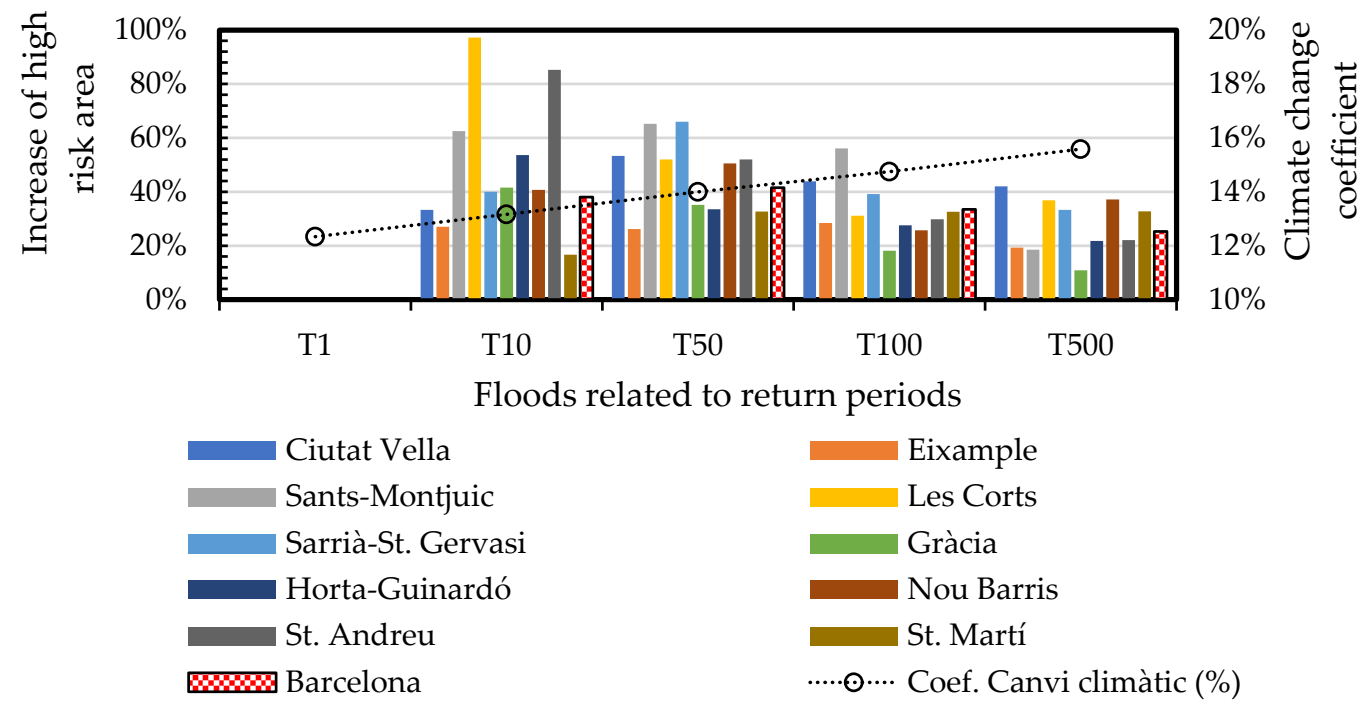

Figure 18. Expected increase of high-risk areas according to the future conditions.

\subsection{Assessment of Economic Impacts Produced by Pluvial Floods}

For the estimation of tangible direct damages caused by pluvial floods generated by urban floods, both properties and vehicles were considered in the economic assessment. According to the claims data provided by the Spanish re-insurance company (CSS), these two risk categories are the most significant.

According to the developed methodology to estimate property damage, flow depths on the streets provided by the 1D/2D USM were properly reduced to achieve flood depths for properties using specific sealing coefficients, which were collected for 14 land uses in Barcelona [35,36]. As a second step, flood damages suffered by the properties were evaluated on the basis of tailored flood depth damage curves for all the 14 land uses; a detailed flood damage model was developed and validated in previous studies [28,30]. Models considered different typologies of properties: without basements, with a basement and with up to two basements. On the other hand, configurations with or without parking access were considered [28,30].

Regarding the evaluation of vehicle damage, a novel methodology-also based on the concept of damage curves-was implemented. The methodology tried to reduce the uncertainty due to the mobility of vehicles, proposing heterogeneous vehicular occupation for several areas of the city based on the information provided by aerial photographs [28,37]. For this assessment, flood damage curves developed by the Army Corps of the United States of America [44] for five types of vehicles were adapted for the case study of Barcelona [28,37]. These curves were converted into a single damage curve weighted according to the percentage of vehicle types in Barcelona, also taking into account their depreciation according to statistical information concerning vehicle types and their age [28,30,37].

For both properties' and vehicles' flood damage assessment, damage maps were achieved for the return periods T1, T10, T50, 100 and T500 and current (baseline) and future (BAU) scenarios and aggregated for each district of the city (Figures 19 and 20). These figures show how future rainfall conditions for a projected storm of 10 years significantly worsen the situation in several districts of the city. Specifically, it can be observed that all the districts of the downtown would suffer high losses, and the better situation of several districts upstream would be exacerbated due to climate change. 
Moreover, for both scenarios, the expected annual damage (EAD) [29] for the whole city including flood damages related to properties and vehicles [30] was calculated. The results indicate that, due to climate change, the EAD would grow from $€ 39.8 \mathrm{M}$ to $€ 54.7 \mathrm{M}$ [28].

Finally, the methodology for the estimation of indirect damages produced by pluvial floods based on an econometric method of input-output (IO) tables indicated a linear relationship between direct and tangible losses. Specifically, according to the obtained results, indirect tangible damages produced by pluvial floods in Barcelona could represent around 29\% of direct damages. This increase could be taken into account in the previously reported EAD [28].

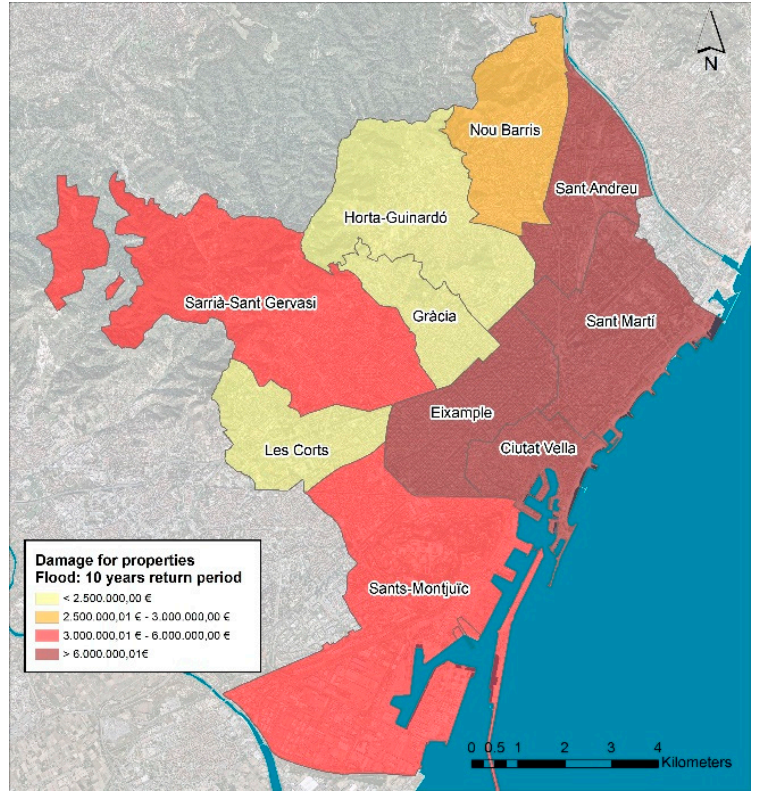

(a)

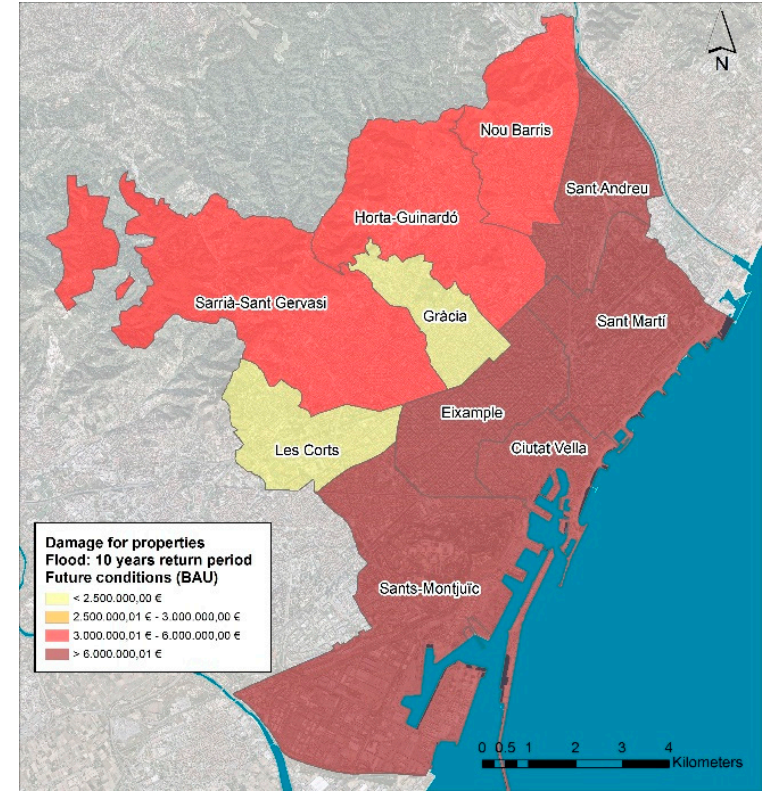

(b)

Figure 19. Example of economic flood damage maps for properties for synthetic projected storms of 10 years related to baseline (a) and BAU scenarios (b) indicating aggregated damages for districts.

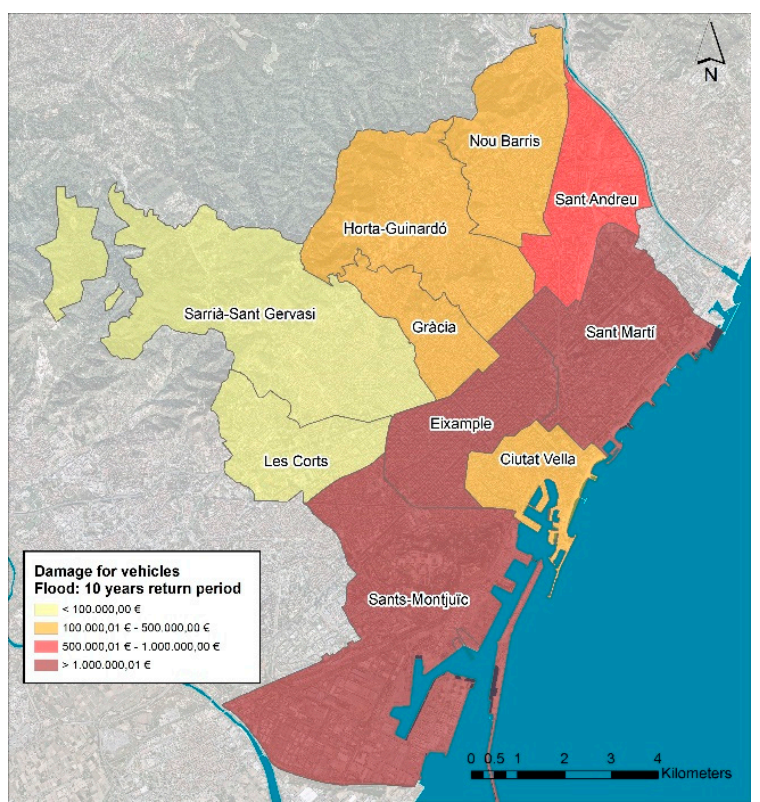

(a)

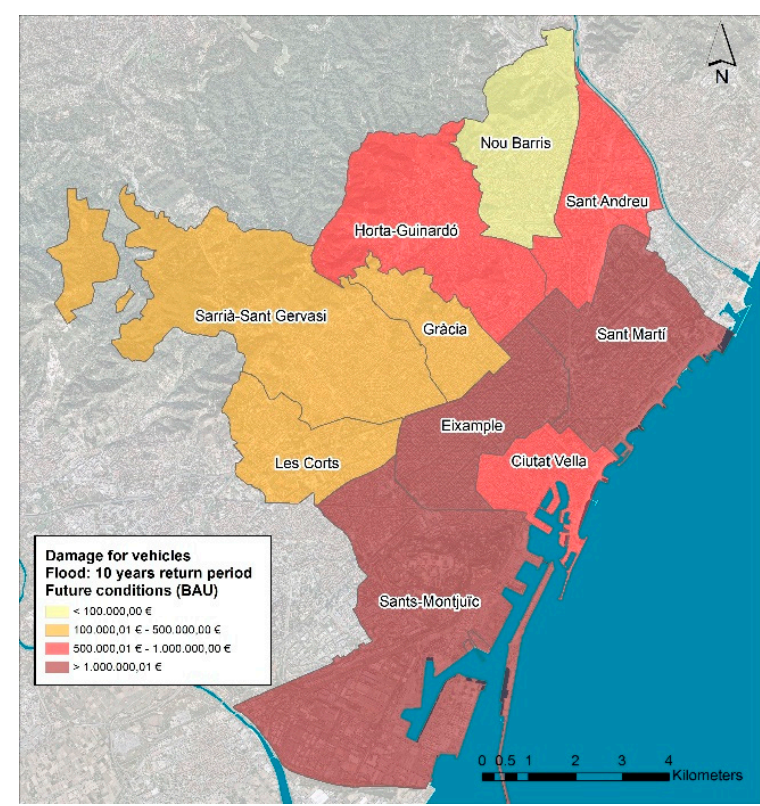

(b)

Figure 20. Example of economic flood damage maps for vehicles for synthetic projected storms of 10 years related to baseline (a) and BAU scenarios (b) indicating aggregated damages for districts. 


\subsection{Assessment of the Effects of Pluvial Floods on the Surface Traffic Service}

The climate-related resilience of a city depends on its capacity to maintain the correct functioning of the main urban services during extreme weather events such as pluvial floods. The results of the impacts produced by this kind of floods on the surface traffic system were analyzed according to the methodology presented in Section 2.7. In this case, flood hazard was assessed through flood hazard maps elaborated on the basis of flood depths provided by the 1D/2D USM and the specific hazard criteria previously presented. Hazard maps were elaborated for the return periods T1, T10, T50, T100 and T500 and current (baseline) and future (BAU) scenarios. Examples of flood hazard maps are shown in Figure 21. Comparing the results for both scenarios, it can be observed that, for the total amount of $1492 \mathrm{~km}$, the increase of the road links that could be affected by speed reduction ranged between $3 \%$ and $30 \%$ depending on the return period, while the increase in terms of closed road links could be around $20 \%$ for all the considered return periods (Figure 22).

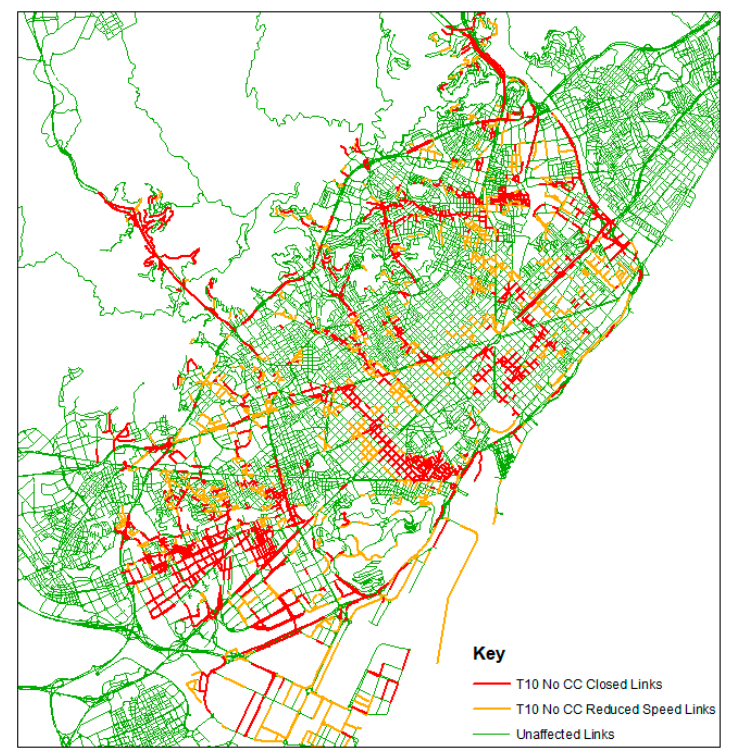

(a)

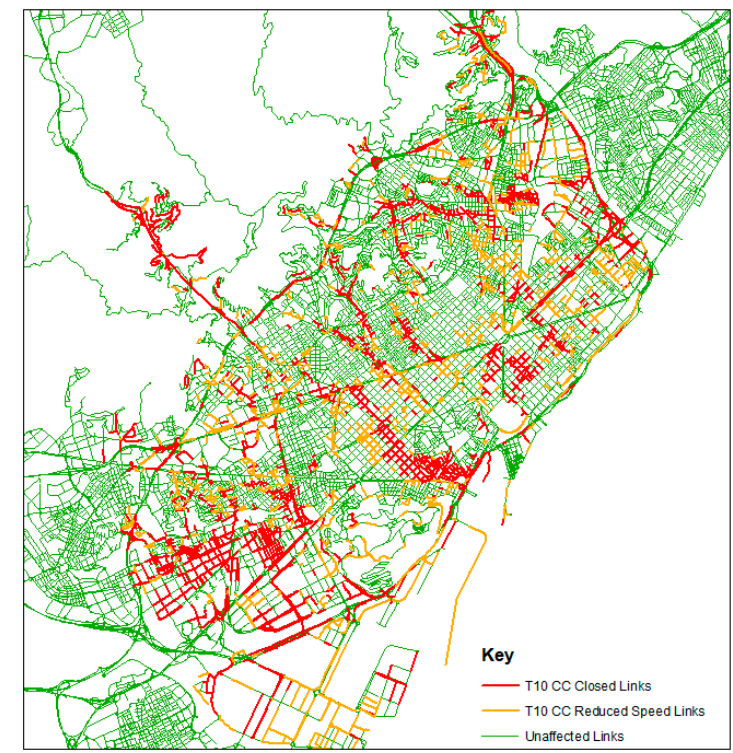

(b)

Figure 21. Example of flood hazard maps for surface traffic for synthetic projected storms of 10 years related to baseline (a) and BAU scenarios (b).

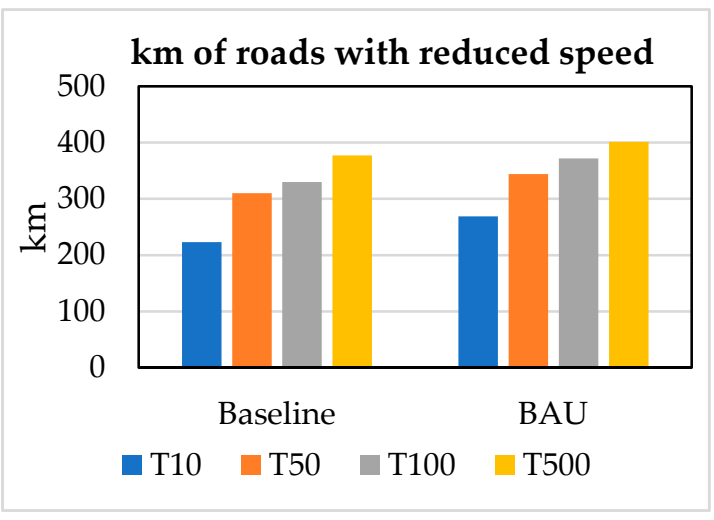

(a)

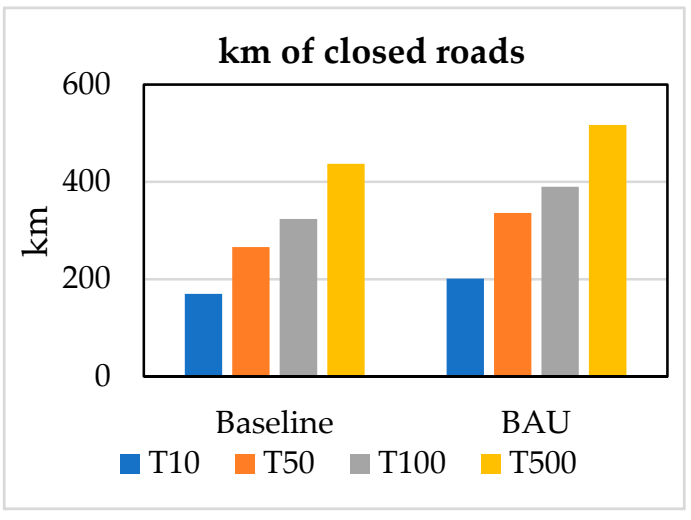

(b)

Figure 22. Representation of the effects produced by pluvial flood on the surface transport system in Barcelona for current (baseline) and future (BAU) scenarios in terms of $\mathrm{km}$ of roads with reduced speed (a) and $\mathrm{km}$ of closed roads (b). 
Finally, through the TransCAD mesoscalar traffic model, the increase in transit time for all the synthetic storm events was assessed and monetized following the methodology proposed by the Multi-Color Handbook [45]. The monetization of the increase of traveling time for the whole city allowed the estimation of a specific EAD for baseline (1.82 M€) and BAU (2.0 M€) [28,38].

\subsection{Assessment of the Effects of Pluvial Floods on the Electric System}

Through the maximum flow depths provided by the 1D/2D USM and the geolocation of electrical infrastructures, an impact analysis was carried out according to the methodology presented in Section 2.8.

Figure 23 shows an example of the risk assessment carried out for all the electrical assets for return periods of T10 and T100. Here, it is possible to see the most affected areas and electrical assets, which are classified within the categories specified in Table 3 and sized with respect to their failure risk. It is possible to observe that the area near the Besòs riverside is clearly the most affected by pluvial flooding, showing the densest cloud of affected locations. Additionally, the figure shows the increase of the failure probability from the blue-colored baseline scenario (BAS) to the BAU scenario, colored in green.

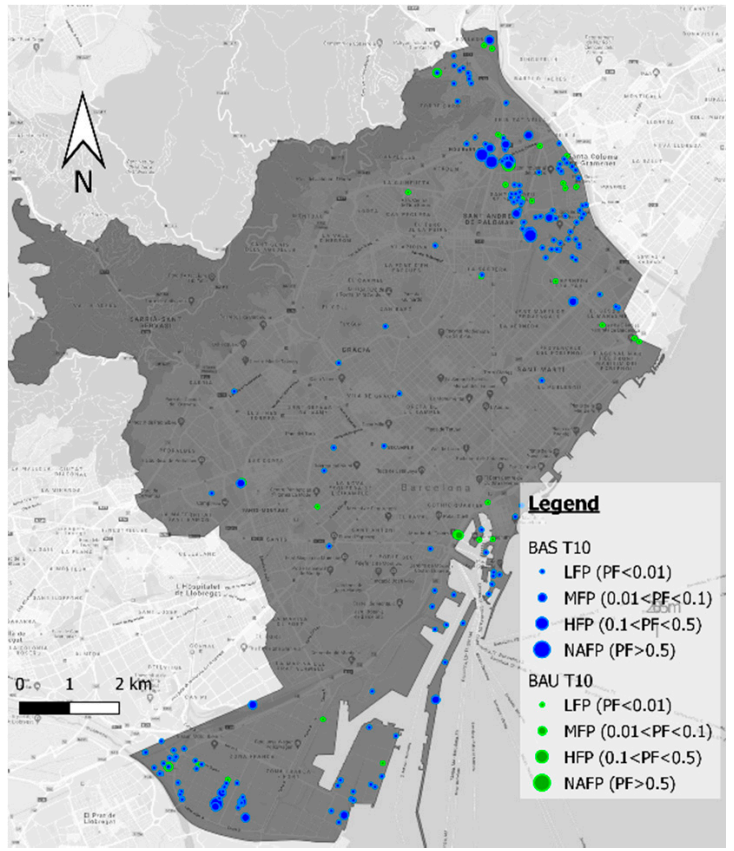

(a)

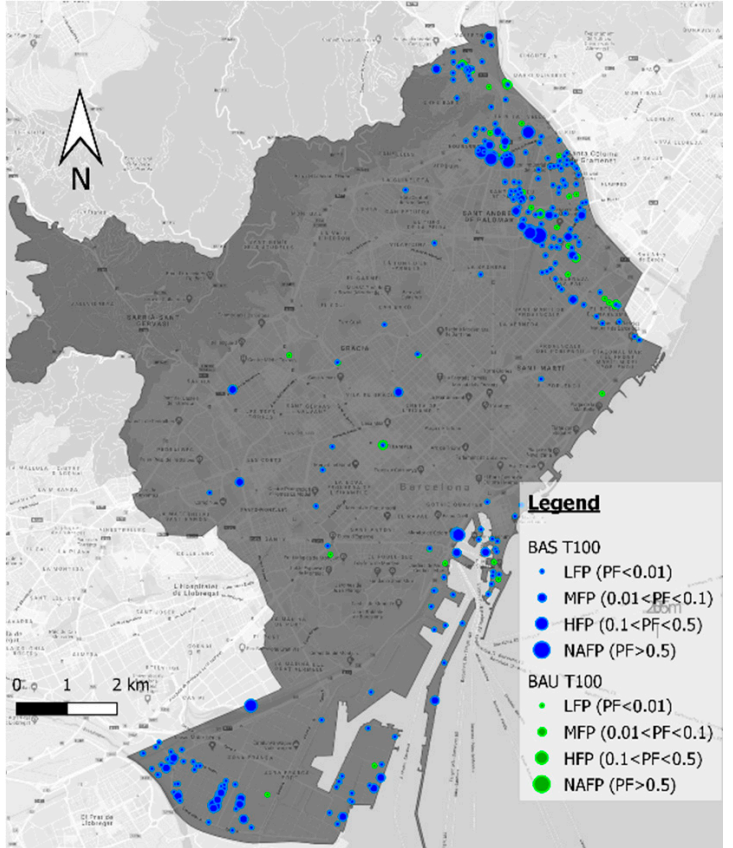

(b)

Figure 23. Example of risk maps of all the electrical assets studied for T10 (a) and T 100 (b).

Table 4 shows the number of electrical infrastructures potentially affected by pluvial flood in Barcelona for baseline and BAU scenarios and their potential level of impact. The table also shows the social impact that each type of flooding provokes in society by counting the number of people affected in each case (reaching, in the worst case, 725,119 out 1,620,343 total people in Barcelona) and the losses provoked for each case, which in the worst scenario amounts to 771,129.01€. It should be noted that the high (HV) and medium-voltage (MV) substations with a potential flood risk have been studied throughout the city, while only the distribution centers (DCs) in the vicinity of Besós and Llobregat rivers and coastal areas were considered $[28,40]$. 
Table 4. Electrical infrastructure potentially affected by pluvial flood in Barcelona for baseline (BAS) and BAU scenarios. DC: distribution center; HV: high-voltage substation; MV: medium-voltage substation.

\begin{tabular}{|c|c|c|c|c|c|}
\hline Return Period & Scenario & $\begin{array}{l}\text { Type of } \\
\text { Location }\end{array}$ & $\begin{array}{c}\text { Number of } \\
\text { Locations Affected }\end{array}$ & $\begin{array}{l}\text { Customers } \\
\text { Affected }\end{array}$ & $\begin{array}{c}\text { Costs } \\
\text { Provoked }\end{array}$ \\
\hline \multirow{6}{*}{ T10 } & \multirow{3}{*}{ BAS } & $\mathrm{DC}$ & 165 & 14,984 & $90,403.68 €$ \\
\hline & & $\mathrm{HV}$ & 6 & 116,872 & $2377.23 €$ \\
\hline & & MV & 11 & 94,231 & $5585.61 €$ \\
\hline & \multirow{3}{*}{ BAU } & DC & 187 & 290,613 & $192,823.10 €$ \\
\hline & & $\mathrm{HV}$ & 6 & 116,872 & $3709.35 €$ \\
\hline & & MV & 13 & 150,723 & $2231.57 €$ \\
\hline \multirow{6}{*}{$\mathrm{T} 50$} & \multirow{3}{*}{ BAS } & DC & 227 & 295,490 & $304,720.21 €$ \\
\hline & & HV & 6 & 116,872 & $11,267.27 €$ \\
\hline & & MV & 13 & 372,311 & $6627.44 €$ \\
\hline & \multirow{3}{*}{ BAU } & $\mathrm{DC}$ & 254 & 314,932 & $476,756.76 €$ \\
\hline & & HV & 7 & 116,872 & $20,367.44 €$ \\
\hline & & MV & 15 & 372,311 & $18,549.21 €$ \\
\hline \multirow{6}{*}{ T100 } & \multirow{3}{*}{ BAS } & DC & 249 & 314,044 & $451,294.19 €$ \\
\hline & & $\mathrm{HV}$ & 7 & 116,872 & $19,438.12 €$ \\
\hline & & MV & 13 & 372,311 & $12,771.98 €$ \\
\hline & \multirow{3}{*}{ BAU } & DC & 272 & 315,991 & $556,183.29 €$ \\
\hline & & $\mathrm{HV}$ & 8 & 116,872 & $28,873.49 €$ \\
\hline & & MV & 15 & 581,566 & $41,375.86 €$ \\
\hline \multirow{6}{*}{ T500 } & \multirow{3}{*}{ BAS } & DC & 296 & 318,232 & $633,795.69 €$ \\
\hline & & HV & 9 & 215,368 & $56,870.91 €$ \\
\hline & & MV & 17 & 582,487 & $28,035.45 €$ \\
\hline & \multirow{3}{*}{ BAU } & DC & 324 & 320,679 & $771,129.01 €$ \\
\hline & & $\mathrm{HV}$ & 11 & 215,368 & $66,869.66 €$ \\
\hline & & MV & 18 & 725,119 & $53,948.15 €$ \\
\hline
\end{tabular}

\subsection{Assessment of the Effects of Pluvial Floods on Waste Collection System}

The integrated flood-waste collection model allowed the estimation of the potential number of unstable containers and their location on specific hazard maps based on their typology and degree of filling for the return periods T1, T10 and T50 [27,28,42]. This analysis showed that, for the most extreme episode (T50), some districts of the city such as Ciutat Vella and l'Eixample could have between 20\% and $25 \%$ of their containers dragged due to the flow and that, in some cases, this amount could increase to values above $30 \%$ for the BAU scenario. Figure 24 shows, as an example, the computed number of containers which are potentially unstable for each district under the assumptions of current and future rainfall conditions for a designed 10 year return period storm. 


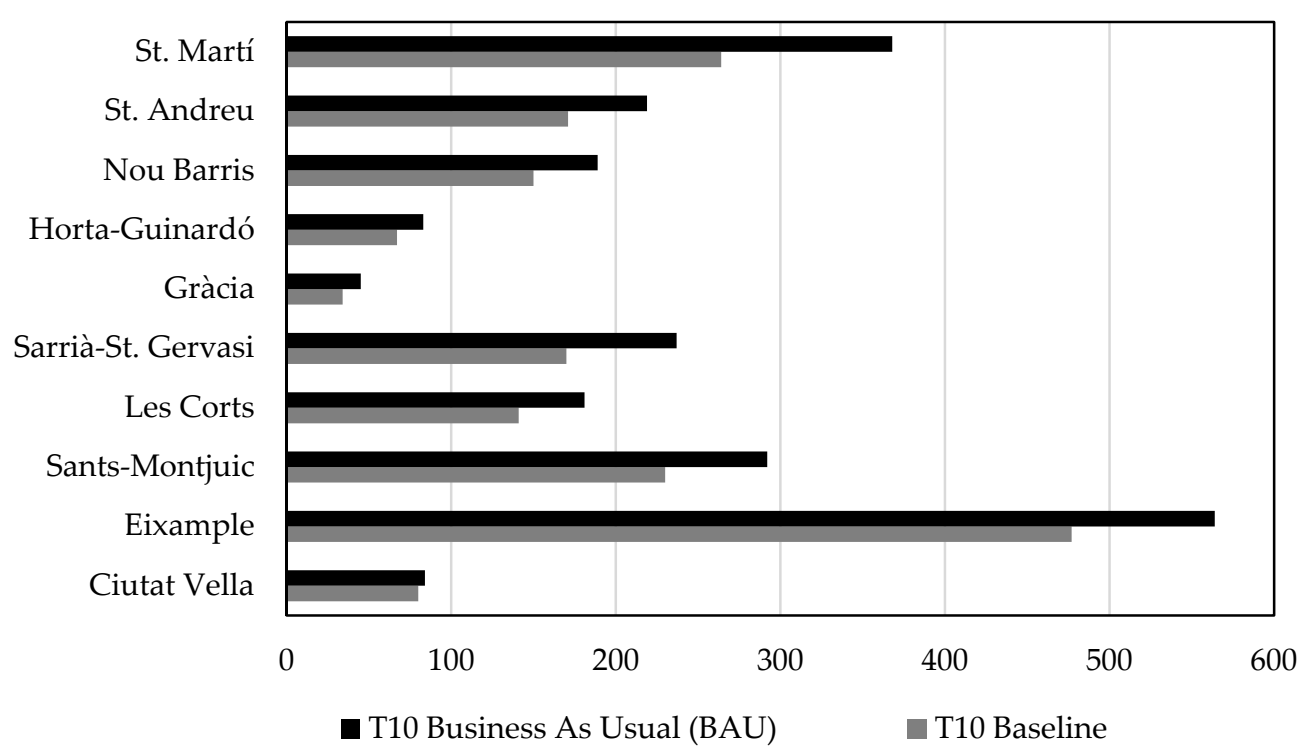

Figure 24. Distribution of computed number of containers which are potentially unstable for each district under current (baseline) and future (BAU) rainfall conditions due to a flooding corresponding to a designed 10 year storm.

\subsection{Assessment of Flood Resilience through a Holistic Approach}

The holistic model was used to determine the recovery time of the city in the case of extreme episodes of pluvial flooding produced by extreme rain events. The analysis of the holistic simulations allowed the estimation of a recovery time of approximately $1.5 \mathrm{~h}$ (calculated as an average value for all the events with return periods T1, T10, T50, 100 and T500), while for the BAU scenario, this value increased up to $2 \mathrm{~h}$.

\section{Discussion}

The potential increase of maximum rainfall intensities in Barcelona due to climate change could produce a significant increase of tangible and intangibles impacts due to pluvial floods. This paper aimed to perform a comprehensive multi-risk assessment using a detailed 1D/2D USM and several loosely coupled models in order to estimate direct impacts not only due to the poor efficiency of the drainage systems of the city but also due to several cascading effects on other critical urban services. This kind of analysis represents a key tool for decision makers to achieve a reliable estimation of the cost of not acting and to propose and justify correct adaptation measures which are able to reduce a large set of tangible and intangible impacts. For the case of Barcelona, the development and calibration of a 1D/2D USM and its integration in several loosely coupled (or integrated) models allowed us to perform a multi-risk analysis whose main important outputs are shown in Table 5. Moreover, the geographic detailed analysis of the potential flood impacts could help in the prioritization of the implementation of adaptation measures [46]. For example, the results provided by some impact models concerning intangible (safety for pedestrians and vehicles, stability of containers) and tangible (economic losses for properties and vehicles) damage indicate that the highest economic and social risks are concentrated in the districts located in the downtown of the city (near the sea). 
Table 5. Potential pluvial flood impacts due to climate change assessed by loosely coupled models.

\begin{tabular}{|c|c|c|c|}
\hline Model & Type of Impact & $\begin{array}{l}\text { Indicator (BAU } \\
\text { vs. Baseline) }\end{array}$ & Values for T/EAD \\
\hline 1D/2D USM & Intangible & $\begin{array}{l}\text { Increase }(\%) \text { of high } \\
\text { flood risk area for } \\
\text { pedestrian and vehicles }\end{array}$ & $\begin{array}{c}\text { Pedestrians: }+30(\mathrm{~T} 10),+34 \\
\text { (T50), +32 (T100), +30 (T500) } \\
\frac{\text { Vehicles: }+38(\mathrm{~T} 10),+42(\mathrm{~T} 50),}{+34(\mathrm{~T} 100),+25(\mathrm{~T} 500)}\end{array}$ \\
\hline $\begin{array}{l}\text { 1D/2D USM + } \\
\text { Damage model }\end{array}$ & Tangible & $\begin{array}{c}\text { Increase }(\%) \text { of EAD } \\
\text { (including properties, } \\
\text { vehicles and indirect } \\
\text { damages) }\end{array}$ & $+42 \%$ \\
\hline $\begin{array}{l}\text { 1D/2D USM + } \\
\text { Traffic model }\end{array}$ & Tangible and Intangible & $\begin{array}{l}\text { Increase }(\%) \text { of } \mathrm{km} \text { of } \\
\text { closed roads; EAD due to } \\
\text { travelling time rise }\end{array}$ & $\begin{array}{c}+31(\mathrm{~T} 10),+60(\mathrm{~T} 50),+66 \\
(\mathrm{~T} 100),+116(\mathrm{~T} 500) ;+0.18 \mathrm{M} €\end{array}$ \\
\hline $\begin{array}{l}\text { 1D/2D USM + } \\
\text { Electric model }\end{array}$ & Tangible and Intangible & $\begin{array}{l}\text { Increase }(\%) \text { of the } \\
\text { number of flooded } \\
\text { electric infrastructures; } \\
\text { related EAD }\end{array}$ & $\begin{array}{c}+13(\mathrm{~T} 10),+12(\mathrm{~T} 50),+11 \\
(\mathrm{~T} 100),+10(\mathrm{~T} 500) ;+0.12 \mathrm{M} €\end{array}$ \\
\hline $\begin{array}{l}\text { 1D/2D USM + } \\
\text { Waste model }\end{array}$ & Intangible & $\begin{array}{l}\text { Increase }(\%) \text { of the } \\
\text { number of unstable } \\
\text { waste containers }\end{array}$ & $\begin{array}{l}\text { Empty: }+27 \text { (T10), +28 (T50) } \\
\text { 50\% full: }+28(\mathrm{~T} 10),+32(\mathrm{~T} 50) \\
\text { 100\% full: }+28 \text { (T10), +36 (T50) }\end{array}$ \\
\hline
\end{tabular}

\section{Conclusions}

This paper demonstrates how the integration of a detailed and calibrated 1D/2D USM with other models and tools which are able to describe the behavior of other urban services can be useful to simulate the response of these services during pluvial floods produced by heavy storm events.

Furthermore, through the development of these loosely coupled models, socio-economic impacts related to these events can be estimated and the cascading effects can be fully analyzed, as well as the interrelationships between services and critical infrastructures.

In this study, the effects of floods in the potential context of climate change for the city of Barcelona have been analyzed through a multi-risk approach, and the results of this assessment, in terms of tangible and intangible impacts, have been presented for the whole city and with a geographic discretization (i.e., in terms of city districts).

The results demonstrate that Barcelona could suffer a significant increase in these impacts due to climate change if adaptation measures are not adopted. It was demonstrated that increments of maximum rainfall intensity of $12-16 \%$ could cause increments of more than $25-30 \%$ in terms of social impacts (e.g., intangible damages such as the increase of areas classified with high hazard conditions in case of pluvial flood events) and of $42 \%$ of economic losses (including tangible direct and indirect damages) expressed in monetary terms through the concept of EAD that has been calculated for each analyzed urban district. Economic losses related to traffic disruption due to pluvial floods could also increase by $9 \%$, while for the electric system, the increase of economic damage could be $70 \%$, although the final EAD result was shown to be quite low.

Moreover, the average recovery time of the city (defined as the time in which urban services do not recover their normal functioning) could increase from 1.5 to $2 \mathrm{~h}$ due to climate change effects.

Finally, the paper shows the geographical distribution of the socio-economic impacts. This information could be very useful for the prioritization of implementation of adaptation measures.

Author Contributions: Conceptualization, B.R.; methodology, B.R., M.V., L.L., E.M.-G., R.M., B.E. and D.S. and D.S.-M; validation, B.R. and M.V.; formal analysis, B.R. and E.M.-G.; investigation, B.R., M.V., L.L., R.M., D.S.-M., E.M.-G., and B.E.; resources, D.S., E.M.-G., B.E. and D.S.-M.; data curation, D.Y., D.S., E.M.-G., E.F.-O., B.E., D.S.-M., A.G.G., writing—original draft preparation, B.R.; writing—review and editing, B.R., M.V., L.L., D.S., E.M.-G., B.E. and D.S.-M; visualization, E.M.-G.; supervision, M.V.; project administration, B.R.; funding acquisition, B.R. and E.M.-G. All authors have read and agreed to the published version of the manuscript. 
Funding: This research was funded by Horizon2020 Programme, Grant Agreement No. 700174.

Acknowledgments: This paper presents some of the results achieved in the framework of the RESCCUE project (Resilience to Cope with Climate Change in Urban Areas-a multisectoral approach focusing on water) (www.resccue.eu). RESCCUE is a research project funded by the European Commission under the H2020 program, and its main goal is to provide methodologies and tools for the evaluation, planning and management of urban resilience in the context of climate change.

Conflicts of Interest: The authors declare no conflict of interest.

\section{References}

1. Meerow, S.; Newell, J.P.; Stults, M. Defining urban resilience: A review. Landsc. Urban Plan. 2016, 147, 38-49. [CrossRef]

2. Velasco, M.; Russo, B.; Martínez, M.; Malgrat, P.; Monjo, R.; Djordjevic, S.; Fontanals, I.; Vela, S.; Cardoso, M.A.; Buskute, A. Resilience to cope with climate change in urban areas-A multisectorial approach focusing on water-The RESCCUE project. Water 2018, 10, 1356. [CrossRef]

3. Walloth, C.; Gurr, J.M.; Schmidt, J.A. Understanding Complex Urban Systems: Multidisciplinary Approaches to Modeling; Springer International Publishing: Cham, Switzerland, 2014; ISBN 978-3-319-02996-2.

4. Visvizi, A.; Lytras, M. Smart Cities: Issues and Challenges. Mapping Political, Social and Economic Risks and Threats, 1st ed.; Lytras, A., Visvizi, M., Eds.; Elsevier: Amsterdam, The Netherlands, 2019; ISBN 9780128166390.

5. Calzada, I.; Almirall, E. Data ecosystems for protecting European citizens' digital rights. Transform. Gov. People Process Policy 2020, 14, 133-147. [CrossRef]

6. Monjo, R.; Paradinas, C.; Gaitán, E.; Redolat, D.; Prado, C.; Pórtoles, J.; Torres, L.; Russo, B.; Velasco, M.; Pouget, L.; et al. Report on Extreme Events Prediction. Deliverable 1.3, RESCCUE EU H2020 Project. Available online: http://www.resccue.eu/ (accessed on 24 April 2020).

7. Hammond, M.J.; Chen, A.S.; Djordjević, S.; Butler, D.; Mark, O. Urban flood impact assessment: A state-of-the-art review. Urban Water J. 2015, 12, 14-29. [CrossRef]

8. Barcelona City Council. Climate Plan 2018-2030; Urban Ecology: Barcelona, Spain, 2018.

9. Monjo, R.; Gaitán, E.; Pórtoles, J.; Ribalaygua, J.; Torres, T. Changes in extreme precipitation over Spain using statistical downscaling of CMIP5 projections. Int. J. Climatol. 2016, 36, 757-769. [CrossRef]

10. Arnbjerg-Nielsen, K. Quantification of climate change effects on extreme precipitation used for high resolution hydrologic design. Urban Water J. 2012, 9, 57-65. [CrossRef]

11. Russo, B. Multi-Hazards Assessment Related to Water Cycle Extreme Events for Future Scenarios-Business As Usual. Deliverable 2.3; RESCCUE EU H2020 Project. Internal report.

12. Hénonin, J.; Russo, B.; Mark, O.; Goubersville, P. Real-time urban flood forecasting and modelling-A state of the art. J. Hydroinform. 2013, 15, 717-736. [CrossRef]

13. Phillips, B.C.; Yu, S.; Thompson, G.R.; Silva, N. De 1D and 2D Modelling of Urban Drainage Systems using XP-SWMM and TUFLOW. In Proceedings of the 10th International Conference on Urban Drainage, Copenhagen, Denmark, 21-26 August 2005; pp. 21-26.

14. Lipeme Kouyi, G.; Fraisse, D.; Rivière, N.; Guinot, V.; Chocat, B. 1D modelling of the interactions between heavy rainfall-runoff in urban area and flooding flows from sewer network and river. In Proceedings of the 11th International Conference on Urban Drainage, Edinburgh, UK, 31 August-5 September 2008.

15. Obermayer, A.; Guenthert, F.W.; Angermair, G.; Tandler, R.; Braunschmidt, S.; Milojevic, N. Different approaches for modelling of sewer caused urban flooding. Water Sci. Technol. 2010, 62, 2175-2182. [CrossRef]

16. Leandro, J.; Chen, A.S.; Djordjević, S.; Savić, D.A. Comparison of 1D/1D and 1D/2D coupled (sewer/surface) hydraulic models for urban flood simulation. J. Hydraul. Eng. 2009, 135, 495-504. [CrossRef]

17. Kandori, C.; Willems, P. Impact of the two-directional interaction of sewer and river systems on the flood risk. In Proceedings of the 11th International Conference of Urban Drainage, Edinburgh, UK, 31 August-5 September 2008; pp. 1-10.

18. Mark, O.; Weesakul, S.; Apirumanekul, C.; Aroonnet, S.B.; Djordjevic, S. Potential and limitations of 1D modelling of urban flooding. J. Hydrol. 2004, 299, 284-299. [CrossRef]

19. Pina, R.D.; Ochoa-Rodriguez, S.; Simões, N.E.; Mijic, A.; Marques, A.S.; Maksimović, Č. Semi- vs. Fully-distributed urban stormwater models: Model set up and comparison with two real case studies. Water 2016, 8, 58. [CrossRef] 
20. Russo, B.; Sunyer, D.; Velasco, M.; Djordjevic, S. Analysis of extreme flooding events through a calibrated 1D/2D coupled model: The case of Barcelona (Spain). J. Hydroinform. 2015, 17, 473-491. [CrossRef]

21. Gómez, M.; Russo, B. Methodology to estimate hydraulic efficiency of drain inlets. Proc. Inst. Civ. Eng. Water Manag. 2011, 164, 81-90. [CrossRef]

22. Gómez, M.; Russo, B. Hydraulic efficiency of continuous transverse grates for paved areas. J. Irrig. Drain. Eng. 2009, 135. [CrossRef]

23. Gómez, M.; Parés, J.; Russo, B.; Martínez-Gomariz, E. Methodology to quantify clogging coefficients for grated inlets. Application to SANT MARTI catchment (Barcelona). J. Flood Risk Manag. 2019, 12. [CrossRef]

24. Gómez, M.; Rabasseda, G.H.; Russo, B. Experimental campaign to determine grated inlet clogging factors in an urban catchment of Barcelona. Urban Water J. 2013, 10. [CrossRef]

25. Innovyze. InfoWorks Integrated Catchment Modelling (ICM), version 10.0; Innovyze: Monrovia, CA, USA, 2020.

26. Russo, B.; Pouget, L.; Malgrat, P. Evaluacion del impacto del cambio climatico en un caso de estudio de Barcelona a través de una modelización 2D-1D del drenaje dual. In Proceedings of the Jornadas de Ingeniería del Agua (JIA), Barcelona, Spain, 5-6 October 2011.

27. Russo, B. Multi-Hazards Assessment Related to Water Cycle Extreme Events for Current Scenario. (Public Summary) Deliverable 2.4. RESCCUE EU H2020 Project. Available online: http://www.resccue.eu/sites/default/files/d2.4. _multi-hazards_assessment_related_to_water_cycle_extreme.pdf (accessed on 24 April 2020).

28. Evans, B. Impact Assessments of Multiple Hazards in Case Study Areas. Deliverable 3.4; RESCCUE EU H2020 Project. Internal report.

29. Velasco, M.; Russo, B.; Cabello, À.; Termes, M.; Sunyer, D.; Malgrat, P. Assessment of the effectiveness of structural and nonstructural measures to cope with global change impacts in Barcelona. J. Flood Risk Manag. 2018, 11. [CrossRef]

30. Martínez-Gomariz, E.; Locatelli, L.; Guerrero, M.; Russo, B.; Martínez, M. Socio-Economic Potential Impacts Due to Urban Pluvial Floods in Badalona (Spain) in a Context of Climate Change. Water 2019, 11, 2658. [CrossRef]

31. Turner, B.L.; Kaspersonb, R.C.; Matsone, P.A.; McCarthy, J.; Corell, R.; Christensene, L.; Eckley, N.; Kasperson, J.X.; Luers, A.; Martello, M.L.; et al. A framework for vulnerability analysis in sustainability science. Proc. Natl. Acad. Sci. USA 2003, 100, 8074-8079. [CrossRef]

32. Russo, B.; Gómez, M.; Macchione, F. Pedestrian hazard criteria for flooded urban areas. Nat. Hazards 2013, 69, 251-265. [CrossRef]

33. Martínez-Gomariz, E.; Gómez, M.; Russo, B. Experimental study of the stability of pedestrians exposed to urban pluvial flooding. Nat. Hazards 2016, 82, 1259-1278. [CrossRef]

34. Martínez-Gomariz, E.; Gómez, M.; Russo, B.; Djordjević, S. A new experiments-based methodology to define the stability threshold for any vehicle exposed to flooding. Urban Water J. 2017, 14, 930-939. [CrossRef]

35. Martínez-Gomariz, E.; Guerrero-Hidalga, M.; Russo, B.; Yubero, D.; Gómez, M.; Castán, S. Desarrollo y aplicación de curvas de daño y estanqueidad para la estimación del impacto económico de las inundaciones en zonas urbanas españolas. Ingenieria del Agua 2019, 23, 229. [CrossRef]

36. Martínez-Gomariz, E.; Forero-Ortiz, E.; Guerrero-Hidalga, M.; Castán, S.; Gómez, M. Flood Depth—Damage Curves for Spanish Urban Areas. Sustainability 2020, 12, 2666. [CrossRef]

37. Martínez-Gomariz, E.; Gómez, M.; Russo, B.; Sánchez, P.; Montes, J.A. Methodology for the damage assessment of vehicles exposed to flooding in urban areas. J. Flood Risk Manag. 2019, 12, 1-15. [CrossRef]

38. Evans, B.; Chen, A.S.; Djordjevi, S.; Webber, J.; Gonzalez, A.; Stevens, J. Investigating the Effects of Pluvial Flooding and Climate Change on Traffic Flows in Barcelona and Bristol. Sustainability 2020, 12, 2330. [CrossRef]

39. Pyatkova, K.H. Flood Impacts on Road Transportation; University of Exeter: Exeter, UK, 2019.

40. Sánchez-Muñoz, D.; Domínguez-García, J.L.; Martínez-Gomariz, E.; Russo, B.; Stevens, J.; Pardo, M. Electrical grid risk assessment against flooding in Barcelona and Bristol cities. Sustainability 2020, 12, 1527. [CrossRef]

41. FEMA. Multi-Hazard Loss Estimation Methodology, Flood Model: Hazus-MH MR4 Technical Manual; FEMA: Washington, DC, USA, 2009.

42. Martínez-Gomariz, E.; Russo, B.; Gómez, M.; Plumed, A. An approach to the modelling of stability of waste containers during urban flooding. J. Flood Risk Manag. 2019. [CrossRef] 
43. Russo, B.; Velasco, M.; Monjo, R.; Martínez-Gomariz, E.; Sánchez, D.; Domínguez, J.L.; Gabàs, A.; Gonzalez, A. Evaluación de la resiliencia de los servicios urbanos frente a episodios de inundación en Barcelona. El Proyecto RESCCUE. Ingenieria del Agua 2020, 24, 101. [CrossRef]

44. U.S. Army Corps of Engineers (USACE). Economic Guidance Memorandum, 09-04, Generic Depth-Damage Relationships for Vehicles; USACE: Washington, DC, USA, 2009.

45. Penning-Rowsell, E.; Viavattene, C.; Pardoe, J.; Chatterton, J.; Parker, D.; Morris, J. The Benefits of Flood and Coastal Risk Management: A Handbook ofAssessment Techniques; Flood Hazard Research Centre, Middlesex University: London, UK, 2010.

46. Guerrero-Hidalga, M.; Martínez-Gomariz, E.; Evans, B.; Webber, J.; Termes-Rifé, M.; Russo, B.; Locatelli, L. Methodology to Prioritize Climate Adaptation Measures in Urban Areas. Barcelona and Bristol Case Studies. Sustainability 2020, 12, 4807. [CrossRef]

(C) 2020 by the authors. Licensee MDPI, Basel, Switzerland. This article is an open access article distributed under the terms and conditions of the Creative Commons Attribution (CC BY) license (http://creativecommons.org/licenses/by/4.0/). 